\title{
Glypican 4 Regulates $A \beta$ Internalization in Neural Stem Cells Partly via Low-Density Lipoprotein Receptor-Related Protein 1
}

\author{
Kaige $\mathrm{Ma}^{1 \dagger}$, Shan Xing ${ }^{2 \dagger}$, Yan Luan ${ }^{1}$, Chenglin Zhang ${ }^{3}$, Yingfei Liu ${ }^{1}$, Yulang Fei ${ }^{4}$, \\ Zhichao Zhang ${ }^{1}$, Yong Liu ${ }^{1}$ and Xinlin Chen ${ }^{1 *}$ \\ 'Institute of Neurobiology, Department of Neurobiology, Xi'an Jiaotong University Health Science Center, Xi'an, China, \\ 2Department of Neonatology, Children's Hospital Affiliated to Zhengzhou University, Henan Children's Hospital, Zhengzhou \\ Children's Hospital, Zhengzhou, China, ${ }^{3} 2018$ Grade, Zonglian College, Xi'an Jiaotong University Health Science Center, \\ Xi'an, China, ${ }^{4}$ Medical College, Xijing University, Xi'an, China
}

OPEN ACCESS

Edited by:

Ulises Gomez-Pinedo,

Instituto de Investigación Sanitaria del Hospital Clínico San Carlos, Spain

Reviewed by: Ahmed Elkamhawy, Mansoura University, Egypt

Laura Garcia-Toscano,

Complutense University of Madrid,

Spain

${ }^{*}$ Correspondence: Xinlin Chen

chenxl@xitu.edu.cn

tThese authors have contributed equally to this work

Specialty section: This article was submitted to Cellular Neuropathology, a section of the journal Frontiers in Cellular Neuroscience

Received: 29 June 2021

Accepted: 16 August 2021 Published: 06 September 2021

Citation:

Ma K, Xing S, Luan Y, Zhang C, Liu Y, Fei $Y$, Zhang $Z$, Liu $Y$ and Chen $X$ (2021) Glypican 4 Regulates $A \beta$ Internalization in Neural Stem Cells Partly via Low-Density Lipoprotein

Receptor-Related Protein 1. Front. Cell. Neurosci. 15:732429. doi: 10.3389/fncel.2021.732429
Neural stem cell (NSC) damage has been reported in patients with Alzheimer's disease. Intracellular A $\beta$ plays a vital role in NSC damage. Heparan sulfate proteoglycans are potent mediators of $A \beta$ enrichment in the brain. We hypothesized the heparan sulfate proteoglycan glypican 4 (Gpc4) regulates $A \beta$ internalization by NSCs. We evaluated Gpc4 expression in NSCs from P0-P2 generations using immunofluorescence. Adenovirus and lentivirus were used to regulate Gpc4 expression in NSCs and APP/PS1 mice, respectively. Co-immunoprecipitation was used to determine the relationship between Gpc4, $A \beta$, and low-density lipoprotein receptorrelated protein 1 (LRP1). Intracellular $A \beta$ concentrations were detected using enzymelinked immunosorbent assay and immunofluorescence. The role of Gpc4/LRP1 on toxic/physical A $\beta$-induced effects was evaluated using the JC-1 kit, terminal deoxynucleotidyl transferase dUPT nick end labeling, and western blotting. Gpc4 was stably expressed in NSCs, neurons, and astrocytes. Gpc4 was upregulated by A $\beta$ in NSCs and regulated $A \beta$ internalization. Gpc4 attenuation reduced $A \beta$ uptake; Gpc4 overexpression increased $A \beta$ uptake. Gpc4 regulated $A \beta$ internalization through LRP1 and contributed to $A \beta$ internalization and toxic/physical concentrations of $A \beta$-induced mitochondrial membrane potential and cell apoptosis, partly via LRP1. Therefore, Gpc4 is a key regulator of A $\beta$ enrichment in NSCs. Inhibiting Gpc4 rescued the $A \beta$-induced toxic effect and attenuated the nontoxic $A \beta$ enrichment into intracellular toxic concentrations. Gpc4 contributed to $A \beta$ internalization and toxic/physical concentrations of $A \beta$-induced mitochondrial membrane potential damage and cell apoptosis, partly via LRP1. These findings suggest a potential role of Gpc4 in treating Alzheimer's disease at an early stage, by targeting NSCs.

Keywords: glypican 4, neural stem cells (NSCs), low density lipoprotein receptor related protein $1, \beta$-amyloid internalization, Alzheimer's disease

Abbreviations: AD, Alzheimer's disease; AdV, adenovirus; ApoE, apolipoprotein E; CCK-8, Cell Counting Kit-8; DAPI, 4',6-diamidino-2-phenylindole; ELISA, enzyme-linked immunosorbent assay; Gpc4, glypican 4; IP, immunoprecipitation; LRP1, low-density lipoprotein receptor-related protein 1; MMP, mitochondrial membrane potential; NSC, neural stem cells; PI, propidium iodide; TUNEL, terminal deoxynucleotidyl transferase dUPT nick end labeling. 


\section{INTRODUCTION}

Neural stem cell (NSC) damage has been reported in the brains of Alzheimer's disease (AD) patients (Wang et al., 2016; Huang et al., 2021). Cognitive decline in AD patients may rise because differentiation of NSCs in the adult brain cannot compensate for neuronal loss.

How does impairment of neurogenesis occur in patients with $A D$ ? Intracellular $\beta$-amyloid peptide $(A \beta)$ aggregation occurs before the extracellular deposition and plaque formation (Bloom, 2014; Tiwari et al., 2019). Intracellular accumulation disrupts the cytoskeletal structure and induces cell apoptosis (Mohamed and Posse de Chaves, 2011). A $\beta$ also induces neuronal toxicity in the early stages of $\mathrm{AD}$ (Oakley et al., 2006). Therefore, understanding the intracellular effects of $A \beta$ will be beneficial for identifying potential targets for $\mathrm{AD}$ treatment. Manipulation of $\mathrm{A} \beta$ transport into NSCs is a promising line of research for the development of $\mathrm{AD}$ therapies.

Heparan sulfate proteoglycans accumulate abundantly in conjunction with $\mathrm{A} \beta$ (Timmer et al., 2010; Fu et al., 2016), and are particularly present in senile plaques (Ghazale et al., 2018). For two decades, the mRNA expression of glypican 4 (Gpc4) has been known to be upregulated in the brains of patients with $\mathrm{AD}$, but its role in the disease remains to be elucidated.

Gpc4 is widely expressed in NSCs, astrocytes, and neurons. Its expression pattern suggests it has multiple roles during nervous system development. Interestingly, the heparan sulfate on the extracellular surface of Gpc4 has a high affinity for $A \beta$ and its receptors, such as low-density lipoprotein receptor-related protein 1 (LRP1) and apolipoprotein E (ApoE; Liu et al., 2013, 2016). This suggests Gpc4 may play an important role in $A \beta$ internalization in NSCs.

In this study, we hypothesized that Gpc4 may assist in $\mathrm{A} \beta$ internalization in NSCs, reducing their viability and facilitating the induction of apoptosis. Our results suggest this may be the case in the early stages of $\mathrm{AD}$. Manipulating the transportation of $A \beta$ into NSCs at an early stage by interfering with Gpc4 is a promising approach for $\mathrm{AD}$ therapeutic studies.

\section{MATERIALS AND METHODS}

All animal experimental protocols were devised in accordance with the National Institute of Health Guide for the Care and Use of Laboratory Animals and approved by the Institutional Animal Care and Use Committee at Xi'an Jiaotong University and. All efforts were made to minimize the number of animals used and their suffering.

\section{NSC Culture}

NSCs were isolated from mouse embryos (E14.5) as previously described (Zhang et al., 2015; Jiao et al., 2016; Ghazale et al., 2018). Epidermal growth factor, fibroblast growth factor, B27, and N2 were added to Dulbecco's Modified Eagle Medium/Nutrient Mixture F-12 as the NSC culture medium. NSCs from the P2 generation were plated at a density of $9 \times 10^{7}$ cells/well. NSCs were transfected with Gpc4 siRNA adenovirus (AdV), according to the manufacturer's instructions
(GeneChem, Shanghai, China). NSCs were treated with AdV for $24 \mathrm{~h}$ and then the medium with AdV was changed to complete medium without AdV. After $72 \mathrm{~h}$ of infection, $A \beta$ was added. Internalization was detected after $6 \mathrm{~h}$, and toxic effects were detected after $12 \mathrm{~h}$.

\section{Cell Viability Assay}

Cell viability was evaluated using the Cell Counting Kit-8 (CCK-8, Sigma-Aldrich, St. Louis, MO, USA) assay. Cells were plated in 96-well plates at 20,000 cells/well density, $24 \mathrm{~h}$ before the experiments. The cells were then treated with different concentrations of $\mathrm{A} \beta(0,200 \mathrm{nM}, 1 \mu \mathrm{M}, 2 \mu \mathrm{M}, 5 \mu \mathrm{M}, 10 \mu \mathrm{M}$, and $20 \mu \mathrm{M}$ ) for $12 \mathrm{~h}$. Next, $20 \mu \mathrm{l}$ of CCK- 8 were added to each well and the cells were incubated for $2 \mathrm{~h}$ at $37^{\circ} \mathrm{C}$. Absorbance was measured at $490 \mathrm{~nm}$ using a microplate spectrophotometer (BioTek, Winooski, VT, USA). Triplicate parallel wells were examined in each experiment, and data were collected from three independent experiments. The results are presented as a percentage of the absorbance compared to the control group.

\section{Terminal Deoxynucleotidyl Transferase dUPT Nick End Labeling (TUNEL) Staining}

To investigate the toxic effect of $A \beta$ on NSC apoptosis mechanism, a terminal deoxynucleotidyl transferase dUPT nick end labeling (TUNEL) assay was performed according to the manufacturer's instructions (Roche Diagnostics, Basel, Switzerland). Cells were fixed on cover slides in $4 \%$ paraformaldehyde for $15 \mathrm{~min}$. The cells were then permeabilized in $0.3 \%$ Triton X-100 in phosphate-buffered saline for $5 \mathrm{~min}$ on ice. Cells were incubated in the TUNEL reaction mixture for $1 \mathrm{~h}$ at $37^{\circ} \mathrm{C}$. Subsequently, the cells were counterstained with 4',6-diamidino-2-phenylindole (DAPI; 1:3,000, Sigma-Aldrich) before mounting. Images were taken within $2 \mathrm{~h}$. Nine random fields were counted for each group with a $40 \times$ objective. The ratio was calculated as the percentage of TUNEL-positive cells compared to that of DAPI-positive cells.

\section{Flow Cytometry Analysis}

Flow cytometry analysis was used for the apoptosis tests in this study. The propidium iodide (PI)/Annexin V apoptosis detection kit (BD Biosciences, Franklin Lakes, NJ, USA) was used according to the manufacturer's instructions. Cells were dissociated, washed in cold phosphate-buffered saline, and resuspended in $1 \times$ binding buffer to obtain a concentration of $1 \times 10^{6}$ cells $/ \mathrm{ml}$. The cells were incubated with PI/Annexin V for $15 \mathrm{~min}$ in the dark. Subsequently, the cell solution was analyzed using FACSCalibur (BD Biosciences) for PI/Annexin V. The percentage of apoptotic cells in this experiment was calculated as the ratio of Annexin V-positive and PI-negative cells from the lower right quarter.

\section{Immunohistochemistry}

For immunohistochemistry performed in APP/PS1 mice, mouse brains were fixed with $4 \%$ paraformaldehyde and frozen coronal slices $(30 \mu \mathrm{m})$ were obtained using a frozen section machine (Leica, Wetzlar, Germany). NSCs were fixed in $4 \%$ paraformaldehyde. The sections were treated with $0.3 \%$ Triton for $30 \mathrm{~min}$. The cells were then blocked with $5 \%$ bovine serum 
albumin for $30 \mathrm{~min}$. The sections were incubated with primary antibodies overnight at $4^{\circ} \mathrm{C}$. The cells were then incubated with the secondary antibodies, goat-anti-rabbit-IgG-488 and goat-anti-mouse-IgG-594 (Invitrogen, Carlsbad, CA, USA), for $2 \mathrm{~h}$ at room temperature. Slides were cover-slipped using a mounting medium containing DAPI (blue). The primary antibodies used in this experiment were: mouse polyclonal anti-nestin antibody (1:200, Novus, St. Louis, MO, USA), rabbit polyclonal anti-Gpc4 antibody (1:100, Abcam, Cambridge, UK), rabbit polyclonal anti-sox2 antibody (1:200, Abcam), rabbit polyclonal anti-Ki67 antibody (1:200, Abcam, Cambridge, UK), mouse polyclonal anti-sox2 antibody (1:200, Abcam, Cambridge, UK), mouse polyclonal anti-LRP1 antibody (1:1,000, Abcam, Cambridge, UK), goat-anti-rabbit-IgG-488, goat-anti-mouseIgG-594 (Invitrogen, Carlsbad, CA, USA), and DAPI (1:3,000, Sigma-Aldrich, USA). For 3,3'-diaminobenzidine staining, we followed the manufacturer's instructions using a secondary antibody staining kit (ZSGB-BIO Inc., Beijing, China).

\section{Western Blotting}

NSCs were homogenized in radioimmunoprecipitation assay buffer supplemented with a protease inhibitor and centrifuged $(15,000 \times g)$ for $30 \mathrm{~min}$ at $4^{\circ} \mathrm{C}$. The protein concentration was quantified using the BCA assay (Beyotime, Nanjing, China). Protein $(10 \mu \mathrm{g})$ was added to each sample, electrophoresed on $10 \%$ sodium dodecyl sulfate polyacrylamide gels, and transferred to a polyvinylidene fluoride membrane (Millipore, Burlington, MA, USA). The membranes were then blocked in 10\% skimmed milk for $2 \mathrm{~h}$ and incubated with the following primary antibodies: rabbit anti-Gpc4 (1:2,000), rabbit anti-Cyt c (1:500), rabbit anti-Bax (1:500), rabbit anti-Bcl 2 (1:500), rabbit anti-GAPDH $(1: 10,000)$, or $\beta$-actin $(1: 10,000)$ (Abcam, Cambridge, UK). The primary antibody was dissolved in $10 \%$ skimmed milk, and the membrane was incubated at $4^{\circ} \mathrm{C}$ overnight. The membrane was then washed and incubated with horseradish peroxidase-conjugated secondary antibody. Membranes were developed using enhanced chemiluminescence and exposed to photographic films. All results were obtained from three independent experiments. The results were analyzed using ImageJ software (Yang et al., 2015).

\section{Virus Infection}

siGpc4, overexpressed Gpc4 (overGpc4), and siLRP1 were coated with $\operatorname{AdV}\left(4 \times 10^{12} \mu \mathrm{g} / \mathrm{ml}\right)$ to infect NSC cell cultures. The overGpc4 sequence was obtained from Gene_ID:14735, GenBank: NM_008150. The forward siGpc4 sequence was 5-GGAUGGCAGU GGAUGACUUTT-3 and the reverse was 5-AAGU CAUCCACUGCCAUCCTT-3. The forward and reverse siLRP1 sequences were 5-GCCCAUUGGAUGAGUUUCATT-3 and 5-UGAAACUCAUCCAAUGGGCTT-3, respectively. The lentivirus vector for Gpc4 overexpression was GV367 Ubi-MCSSV40-EGFP-IRES-pruromycin (GENE, Shanghai, China), and the lentivirus vector for siGpc4 was hU6-MCS-Ubiquitin-FGFPIRES-puromycin (GENE, Shanghai, China). AdV was plated into 6-well plates at a density of $2 \times 10^{6}$ cells $/ \mathrm{ml} ; 10 \mu \mathrm{l}$ of $2 \times 10^{12}$ $\mu \mathrm{g} / \mathrm{ml} \mathrm{AdV}$ was added to each well in NSC complete medium
(GENE, Shanghai, China). Twenty-four hours after infection, the medium was replaced with a complete medium without AdV. The cells were used for the experiment $72 \mathrm{~h}$ after infection.

\section{Enzyme-Linked Immunosorbent Assay (ELISA)}

$10 \mu \mathrm{l}$ of $2 \times 10^{12} \mu \mathrm{g} / \mathrm{ml} \mathrm{AdV}$ (overGpc4 and si Gpc4) was plated into 6 -well plates at a density of $2 \times 10^{6}$ cells $/ \mathrm{ml}$ (GENE, Shanghai, China). Twenty-four hours after infection, the medium was replaced with a complete medium without AdV. A $\beta$ was added into each 6 -well plates cells at a working concentration of $200 \mathrm{nM}$ or $2 \mu \mathrm{M}, 72 \mathrm{~h}$ after Adv infection. NSC samples were collected $12 \mathrm{~h}$ after $A \beta$ treatment. Mouse $A \beta$ enzyme-linked immunosorbent assay (ELISA) Kit (R\&D Systems, Minneapolis, MN, USA; Ma et al., 2016) and quantification experiments were conducted according to the manufacturer's instructions (R\&D Systems, Minneapolis, MN, USA). Protein samples in each group were detected three times in the 96T ELISA kit. $\mathrm{A} \beta$ concentrations were calculated by the standard curve. This experiment was repeated three times.

\section{APP/PS1 Mice}

The APP/PS1 mice used in this study were double transgenic mice bred by crossing two lines of commercial simple transgenic mice: APPSWE (Tg2576 on a B6J background) and PS1dE9 on a C57BL6SJL background. Acute crossing of these two lines produces an accelerated mouse model of $\mathrm{AD}$ on a B6J/B6SJL background combining cognitive and amyloid pathologies starting at 4 months old. Genotypes were confirmed by a polymerase chain reaction from a tail biopsy. All wild type mice in this study are of B6J/B6SJL littermates. All APP/PS1 mice were APP-and PS1 positive. The animals were obtained by Yang Wei-Na from Xi'an Jiaotong University, housed in an animal facility with two mice per cage in temperature- $\left(22 \pm 1{ }^{\circ} \mathrm{C}\right)$ and humidity-controlled $(50 \pm 10 \%)$ conditions under a $12 \mathrm{~h}$ light/dark cycle. The mice had access to food and water ad libitum for 4 months before being used in the experiment.

Gpc4 siRNA lentivirus was injected into each mouse's brain via stereotaxic surgery under deep isoflurane anesthesia $(n=6)$. Gpc4 siRNA lentivirus was injected using stereotaxic coordinates and a microsyringe. Virus was injected into the lateral ventricles and the CA1 hippocampal subfield (rostrocaudal: $1.0 \mathrm{~mm}$, mediolateral: $1.30 \mathrm{~mm}$, dorsoventral: $1.8 \mathrm{~mm}$ vs. Bregma) of both sides (rostrocaudal: $1.80 \mathrm{~mm}$, mediolateral: $1.00 \mathrm{~mm}$, dorsoventral: $3.10 \mathrm{~mm}$ vs. Bregma). The injection speed was $0.2 \mu \mathrm{l} / \mathrm{min}$, and the total volume/side was $1 \mu \mathrm{l}, 2 \times 10^{8} / \mu \mathrm{l}$. The control virus was also injected into APP/PS1 mice $(n=5)$. After surgery, the animals were given 2 months for recovery and lentivirus expression.

\section{Thioflavin-S Staining}

After the brain was perfusion-fixed and sectioned at $30 \mu \mathrm{m}$ on a freezing microtome, the selected series were mounted onto gelatine-coated glass slides and air-dried. The tissue was hydrated by passing it through a series of ethyl alcohol solutions (100\%, $95 \%, 80 \%$, and $70 \%, 1-2 \mathrm{~min}$ in each) before staining with $1 \%$ Thioflavin-S for $30 \mathrm{~min}$ (Oakley et al., 2006). The slides were 


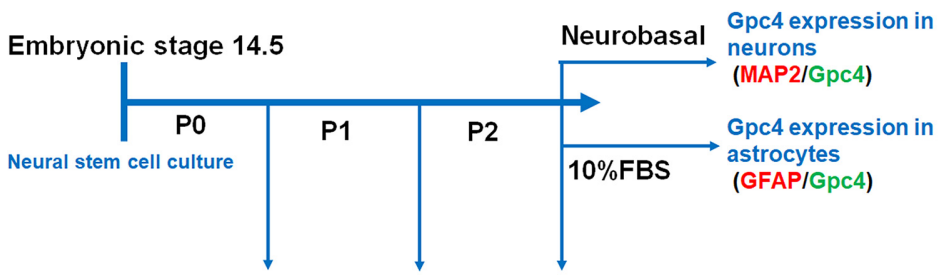

Gpc4 expression in neural stem cells (Nestin/Gpc4)

B
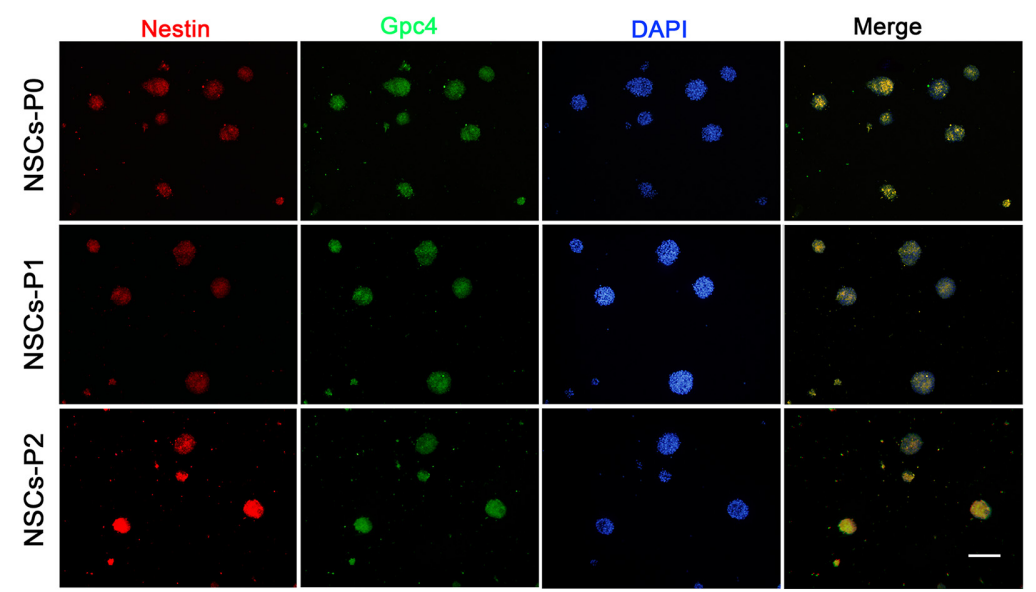

C
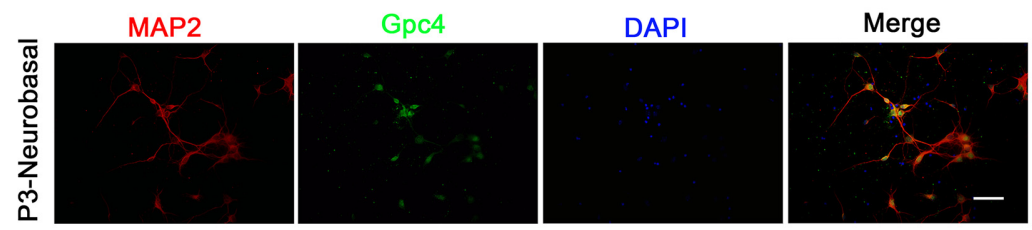

D
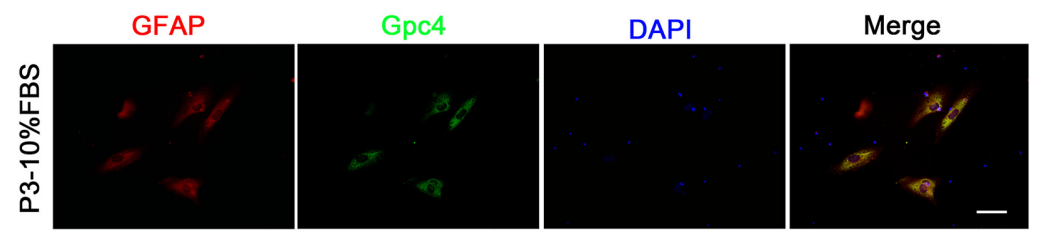

FIGURE 1 | Expression of Gpc4 in neural stem cells (NSCs). (A) The schedule for detecting Gpc4 expression in NSCs and differentiated neurons and astrocytes. (B) At P0, P1, and P2, Gpc4 (green) colocalized with nestin (red) in the neural spheres. (C,D) NSCs were differentiated using neural basal medium containing B27 or DMEM/F12 containing 10\% FBS. MAP2 (red) and GFAP (red) were used to illustrate Gpc4 (green) expression in neurons and astrocytes, respectively. Gpc4, glypican 4; DMEM/F12, Dulbecco's Modified Eagle Medium/Nutrient Mixture F-12.

subsequently rinsed in distilled water and transferred through $80 \%$ and $95 \%$, and two sets of $100 \%$, ethanol for 30 s before coverslipping with mounting media and storage under refrigeration. Thioflavin-S staining was viewed under a green fluorescence microscope $(480 / 525 \mathrm{~nm})$.

\section{Immunoprecipitation Experiment}

Immunoprecipitation (IP; Proteintech, Chicago, IL, USA) was performed as previously described (Ma et al., 2018). Eluted proteins that bind to any protein complex containing Gpc4 were separated via sodium dodecyl-sulfate polyacrylamide gel electrophoresis. Gpc4, LRP1, and A $\beta$ were detected using western blotting. Briefly, APP/PS1 mouse brain tissue supernatants containing $4 \mathrm{mg}$ protein (in approximately $1 \mathrm{ml}$ lysate) were pre-cleared for $1-4 \mathrm{~h}$ at $4^{\circ} \mathrm{C}$ with $100 \mu \mathrm{l}$ of 80-100 protein G. Precleared supernatants were incubated overnight at $4^{\circ} \mathrm{C}$ with the desired IP antibody (MOAB2, 1:200; Gpc4, 1:100; goat anti-rabbit IgG, 1:100) and $200 \mu \mathrm{l}$ of protein $G$ beads. IP complexes were washed five times with wash buffer and eluted twice with $40 \mu$ l elution buffer. Protein complexes $(80 \mu \mathrm{l})$ were obtained and used for western blotting. 

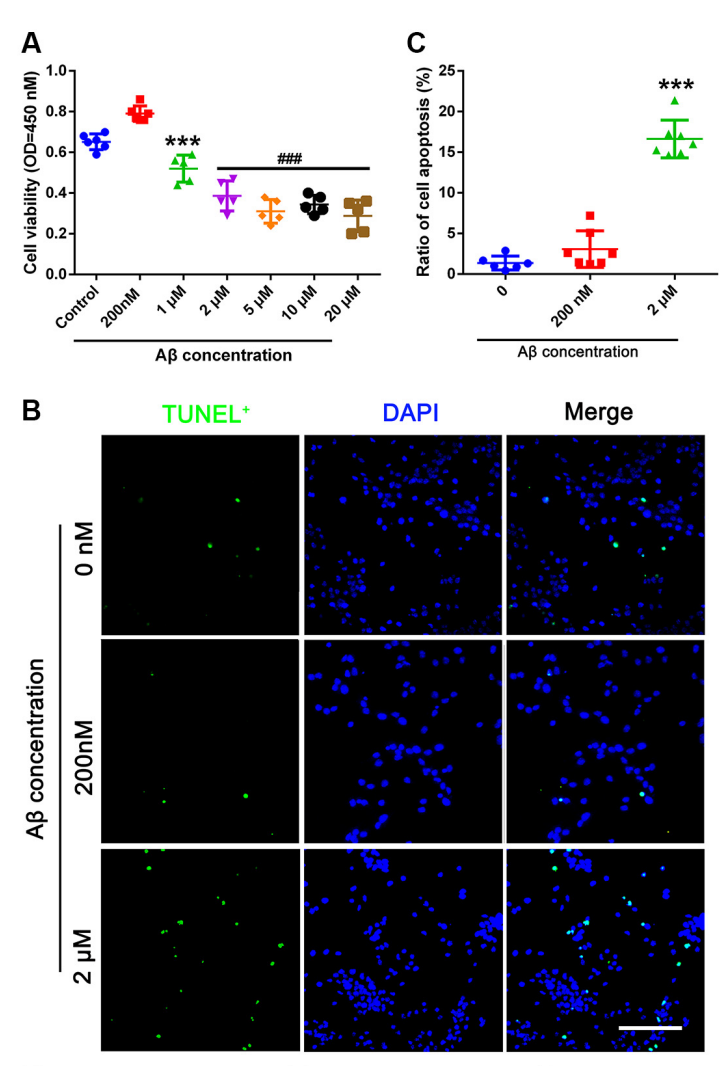

D
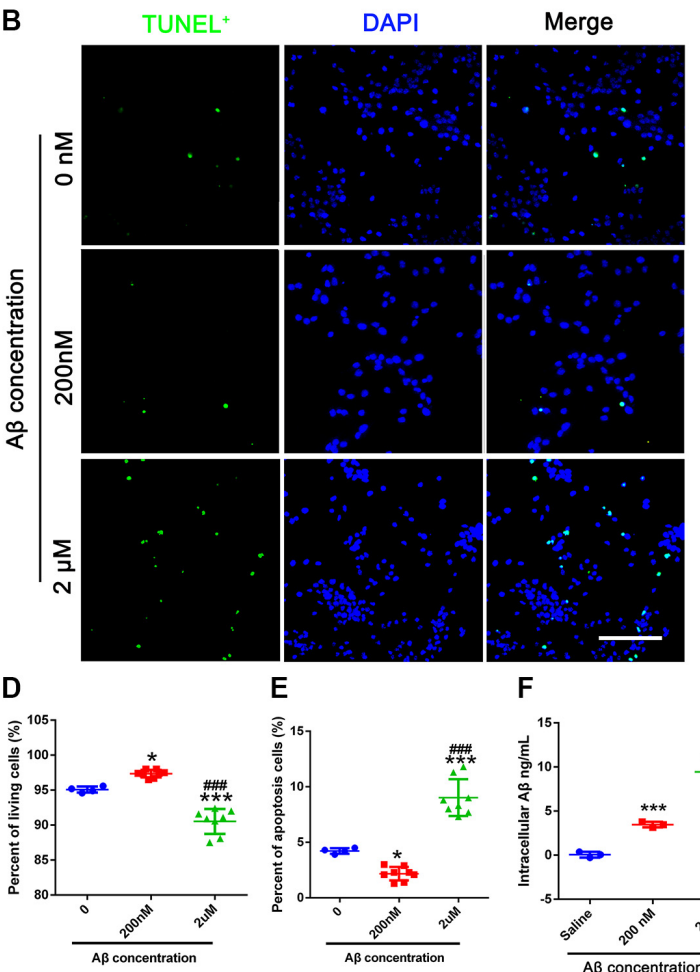

E

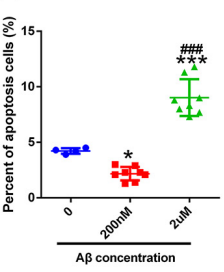

$\mathbf{F}$

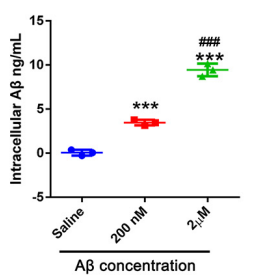

FIGURE 2 | Different concentrations of A 3 affect NSC apoptosis. (A) CCK-8 was used to detect cell viability. NSCs were passed for 2-4 generations and plated into 96-well plates. Different concentrations of $A \beta$ oligo were added for $24 \mathrm{~h}$ before the CCK-8 test. ${ }^{\star \star \star}$ represents $1 \mu \mathrm{M}$ vs. control group, $P=0.011$. \#\#\# represents $2-20 \mu \mathrm{M}$ vs. control group, $P<0.0001$. (B) TUNEL was used to obtain apoptotic cell numbers in $0 \mu \mathrm{M} \mathrm{A} \beta$-, $200 \mathrm{nM} \mathrm{A} \beta$-, and $2 \mu \mathrm{M}$ A $\beta$-treated NSCs. (C) The ratio of TUNEL (green) positive cells compared to DAPI (blue) was calculated. ${ }^{* \star *}$ represents $2 \mu \mathrm{M} \mathrm{A} \beta$ vs. $0 \mu \mathrm{M} \mathrm{A} \beta, P<0.0001$ Scale bar $=50 \mu \mathrm{m}$. (D) NSCs treated with $0 \mu \mathrm{M} \mathrm{A} \beta, 200 \mathrm{nM} \mathrm{A} \beta$, and $2 \mu \mathrm{M}$ $\mathrm{A} \beta$ were harvested $24 \mathrm{~h}$ after $\mathrm{A} \beta$ treatment and stained with $\mathrm{Pl} / \mathrm{AnnexinV}$ for flow cytometry analysis. The percentage of living cells was calculated. *

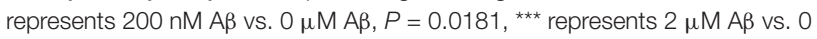
$\mu \mathrm{M} \mathrm{A} \beta, P<0.0001$, \#\#\# represents $2 \mu \mathrm{M} \mathrm{A} \beta$ vs. $200 \mathrm{nM} \mathrm{A} \beta, P<0.0001$.

(E) Cells were treated as mentioned in (D). The percentage of apoptotic cells was calculated. * represents $200 \mathrm{nM} \mathrm{A} \beta$ vs. $0 \mu \mathrm{M} \mathrm{A} \beta, P=0.0236$, *** represents $2 \mu \mathrm{M} \mathrm{A} \beta$ vs. $0 \mu \mathrm{M} \mathrm{A} \beta, P<0.0001$, \#\#\# represents $2 \mu \mathrm{M} A \beta$ vs. $200 \mathrm{nM} \mathrm{A} \beta, P<0.0001$. (F) $0 \mu \mathrm{M}, 200 \mathrm{nM}$, and $2 \mu \mathrm{M} \mathrm{A} \beta$ were added to NSCs for $6 \mathrm{~h}$. Intracellular $A \beta$ was detected using the $A \beta_{1-42}$-ELISA kit. *** represents $200 \mathrm{nM} \mathrm{A} \beta$ vs. $0 \mu \mathrm{M} \mathrm{A} \beta, P=0.0003$, ${ }^{\star \star \star *}$ represents $2 \mu \mathrm{MA} \beta$ vs. 0 $\mu \mathrm{M} \mathrm{A} \beta, P<0.0001$, \#\#\# represents $2 \mu \mathrm{M} \mathrm{A} \beta$ vs. $200 \mathrm{nM} \mathrm{A} \beta$. NSC, neural stem cells; CCK-8, cell counting kit 8; TUNEL, terminal deoxynucleotidyl transferase dUPT nick end labeling; DAPI, 4',6-diamidino-2-phenylindole; PI, propidium iodide; ELISA, enzyme-linked immunosorbent assay.

\section{JC-1 for Mitochondrial Membrane Potential (MMP)}

NSCs were stained with JC-1 to determine the mitochondrial membrane potential (MMP). JC-1 is a membrane-permeable lipophilic dye that exists as JC-1 aggregates in the mitochondrial matrix (red) or as monomers in the cytoplasm (green). During mitochondrial depolarization, the red JC-1 aggregates form green monomers due to a change in proton motive force $(\Delta \Psi)$. Thus, depolarization can be measured as an increase in the green fluorescent/red fluorescent intensity ratio. The JC-1 assay was performed as follows. Solutions containing $5 \mu \mathrm{g} / \mathrm{ml} \mathrm{JC}-1$ were added for $\mathrm{AdV}$ and $\mathrm{A} \beta$ treated NSCs for $30 \mathrm{~min}$. The stained cells were rinsed twice with the culture medium. After the fresh media was added, the cells were analyzed under a green fluorescence microscope $(480 / 525 \mathrm{~nm})$.

\section{Statistical Analyses}

All data were analyzed with GraphPad Prism version 6.0 (GraphPad Software, San Diego, CA, USA). For normal distribution data, one-way analysis of variance (ANOVA) followed with Tukey's multiple comparisons test were performed. $P$-value $<0.05$ was regarded as significant. $t$-test was used to compare between two groups. All in vitro experiments have been independently repeated at least three times. For in vivo experiments, in each group at least five mice were used for statistical analysis.

\section{RESULTS}

\section{Gpc4 Is Expressed in NSCs}

Neural stem cells derived from the cortex of embryonic 14.5 (E14.5) mice were observed. Approximately 5 days after primary culture ( $\mathrm{P} 0)$, the isolated NSCs were passed for the next generation (P1) and then for P2 (Figure 1A). We observed that neural spheres from P0-P2 stably expressed Gpc4 and nestin (Figure 1B). After NSC differentiation, we also detected high colocalization of Gpc4 and both neurons and astrocytes (Figures 1C,D).

\section{Different Concentrations of A $\beta$ Affect NSC Viability and Apoptosis}

This experiment aimed to determine the toxic dose of $A \beta$ in NSCs. We found that $200 \mathrm{nM} \mathrm{A} \beta$ induced cell viability of NSCs, but that 1-20 $\mu \mathrm{M}$ A $\beta$ was toxic to NSCs (Figure 2A). Therefore, $200 \mathrm{nM} \mathrm{A} \beta$ and $2 \mu \mathrm{M} \mathrm{A} \beta$ were used in this study. TUNEL staining showed that the number of apoptotic cells increased in the group treated with $2 \mu \mathrm{M} \mathrm{A} \beta$ compared to the $0 \mu \mathrm{M}$ $A \beta$ group (Figures $2 \mathrm{~B}, \mathrm{C}$ ). We then used flow cytometry to detect $\mathrm{PI} / \mathrm{AnnexinV}$ stained cells. The percentage of living cells in the group treated with $200 \mathrm{nM} \mathrm{A} \beta$ was significantly higher than that in the control group $(0 \mu \mathrm{M} A \beta)$. The percentage of living cells in the $2 \mu \mathrm{M} \mathrm{A} \beta$ group was significantly lower than that in the control group $(0 \mu \mathrm{M} \mathrm{A} \beta)$. The apoptotic and living cell percentage in different concentrations of $A \beta$ on NSCs is contrasting (Figures 2D,E). We used ELISA to detect the intracellular $A \beta$ level. NSCs in the $200 \mathrm{nM}$ group absorbed more $\mathrm{A} \beta$ than those in the control group. Cells treated with $2 \mu \mathrm{M} A \beta$ 
A

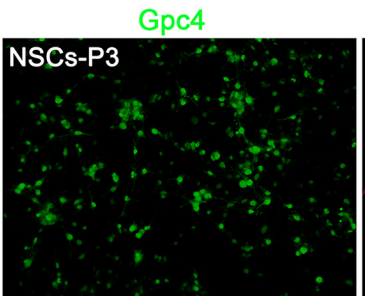

DAPI
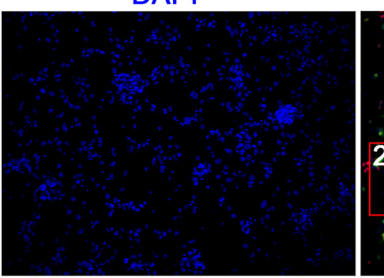

Magnified

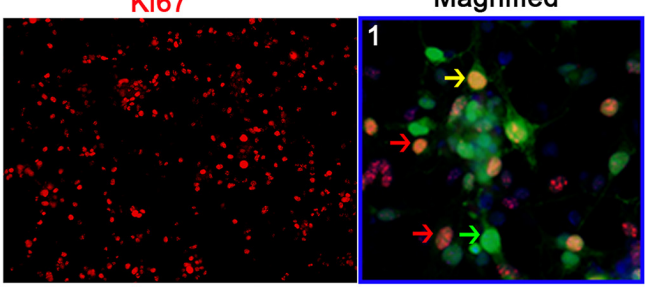

Magnified

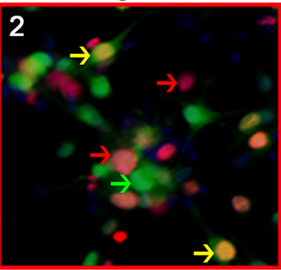

B

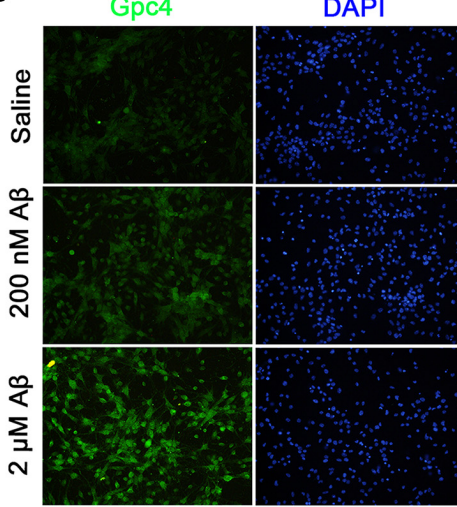

Nestin

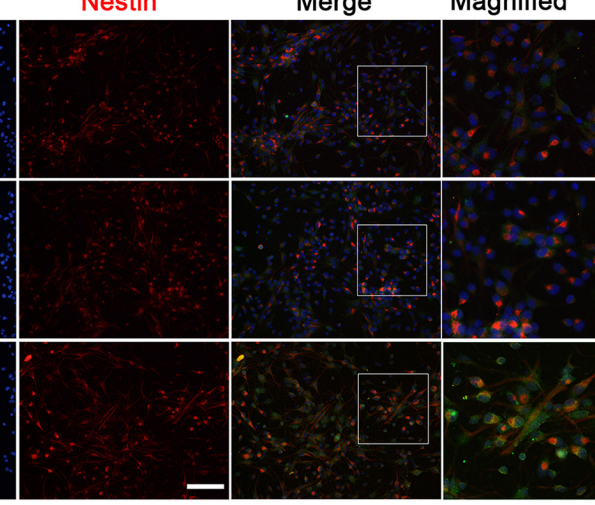

C

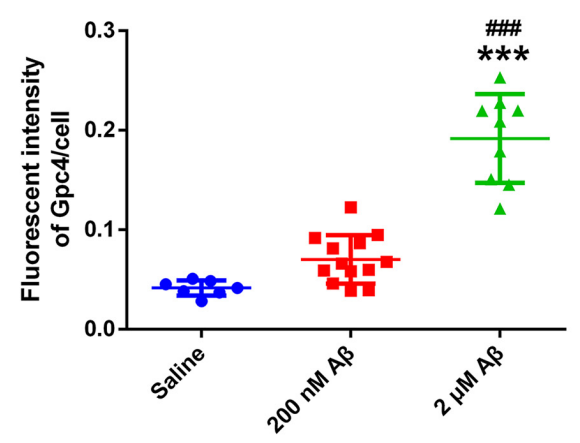

D
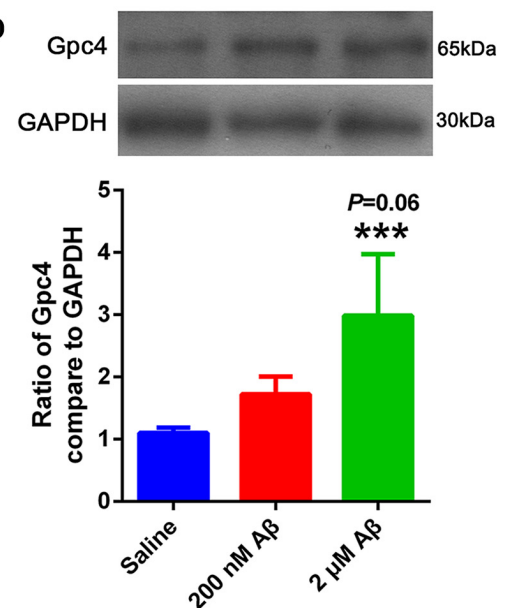

FIGURE 3 | A 3 upregulated Gpc4 expression in NSCs. (A) Immunofluorescence analysis revealing the protein expression of Gpc4 (green) with Ki67 (red) in NSCs. Nuclei were counterstained with DAPI (blue). Gpc4 was widely expressed in NSCs (green). Double positive Gpc4/Ki67 NSCs (yellow arrow), Gpc4-negative Ki67-positive NSCs (red arrow), and Gpc4-positive Ki67-negative NSCs (green arrow) were also observed. Scale bar $=50 \mu \mathrm{m}$. (B,C) NSCs were treated with 0, 200 $\mathrm{nM}$, and $2 \mu \mathrm{M}$ A $\beta$ for $24 \mathrm{~h}$. Immunofluorescence analysis revealed the expression of Gpc4 (green), nestin (red), and DAPI (blue). Gpc4 colocalized with nestin-positive

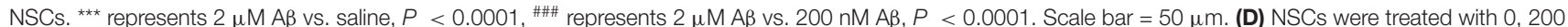
$\mathrm{nM}$, and $2 \mu \mathrm{M} \mathrm{A \beta}$ for $24 \mathrm{~h}$ before western blotting. Western blotting was used to detect Gpc4 (56 kDa) and GAPDH (35 kDa) expression levels. ${ }^{* * *}$ represents $2 \mu \mathrm{M}$ A $\beta$ vs. saline, $P=0.007$. Gpc4, glypican 4; NSCs, neural stem cells; DAPI, 4',6-diamidino-2-phenylindole; GAPDH, glyceraldehyde 3-phosphate dehydrogenase. 


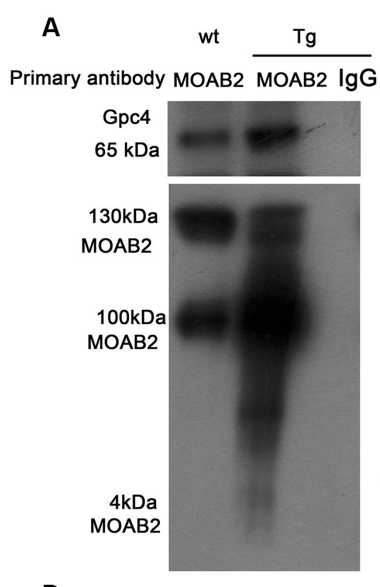

D

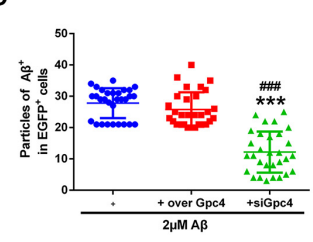

G

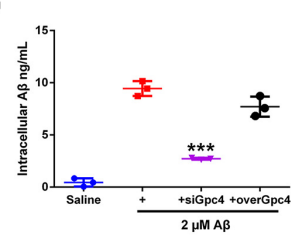

J

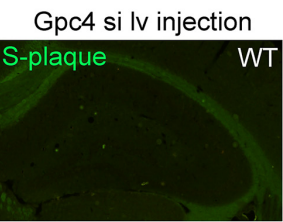

B

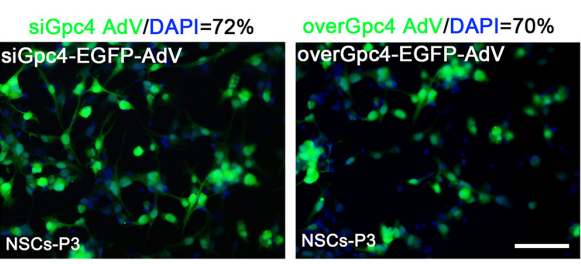

C

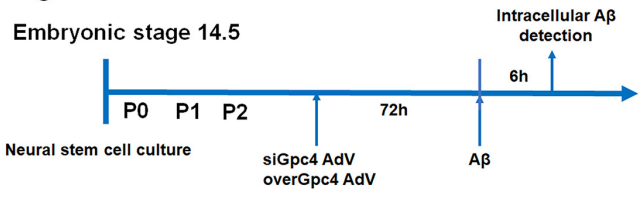

E

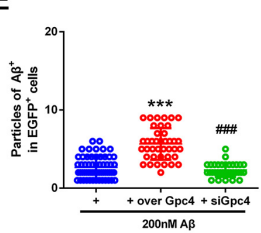

F

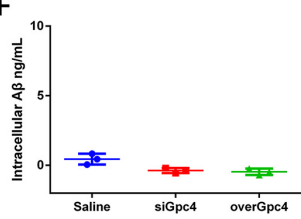

H

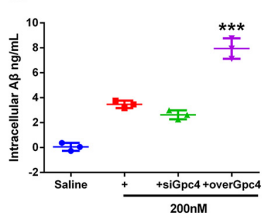

I

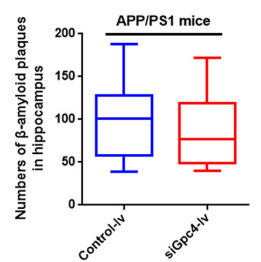

Gpc4 si Iv injection

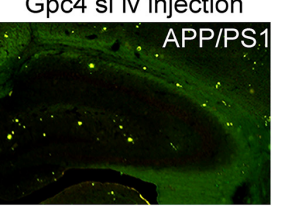

FIGURE 4 | Gpc4 regulates A $\beta$ internalization in NSCs. (A) Co-immunoprecipitation result from protein lysis extracted from 6-month-old APP/PS1 mice. Protein samples were incubated with the primary antibody MOAB2. Protein complexes able to bind to MOAB2 (Aß42) were eluted. Western blotting was used to detect MOAB2 (AB42) and Gpc4 expression. (B) NSCs were plated in complete medium, and $2 \times 10^{12}$ siGpc4 and overGpc4 AdV expression using enhanced green fluorescent protein (green) was added for $24 \mathrm{~h}$. The medium was changed to complete medium, and cells were incubated for $48 \mathrm{~h}$. Nuclei were marked with DAPI (blue). The ratio for AdV infection was calculated. (C) The schedule of virus infection and A $\beta$ treatment on NSC cells. Seventy-two hours after virus infection, A $\beta$ was added. Six hours after adding cy3-A $\beta$, all particles in AdV-positive cells were counted and compared among groups. (D) Six hours after adding $2 \mu M$ cy3-A $\beta$, all particles in AdV-positive cells were counted and compared among groups. ${ }^{\star \star \star}$ represents siGpc4+ $2 \mu \mathrm{M} A \beta$ vs. $2 \mu \mathrm{M} A \beta, P<0.0001$, ${ }^{\# \# \# ~ r e p r e s e n t s ~ s i G p c 4+~}$ $2 \mu \mathrm{M} A \beta$ vs. overGpc4+ $2 \mu \mathrm{M} \mathrm{A \beta}, P<0.0001$. (E) Six hours after adding $200 \mathrm{nM}$ cy3-A $\beta$, all particles in AdV-positive cells were counted and compared among groups. ${ }^{* \star}$ represents overGpc4+ 200 nM A $\beta$ vs. 200 nM A $\beta, P<0.0001$, \#\#\# represents siGpc4+ 200 nM A $\beta$ vs. overGpc4+ 200 nM A $\beta, P<0.0001$. (F) AdV was used to infect NSCs, and intracellular A 342 in NSCs was detected using ELISA. (G) NSCs were treated as previously described in (C). Instead of cy3-A $\beta$, the $\mathrm{A} \beta 42$ were used in this experiment. Six hours after adding $2 \mu \mathrm{M} \mathrm{A} \beta 42, \mathrm{~A} \beta 42$ levels were detected using ELISA. ${ }^{* \star *}$ represents siGpc4+ $2 \mu \mathrm{M} A \beta$ vs. $2 \mu \mathrm{M} A \beta$, $P<0.0001$. (H) NSCs were treated as previously described in (G). Six hours after adding 200 nM A $\beta 42$, A 442 levels were detected using ELISA. ${ }^{\star \star \star}$ represents overGpc4+ 200 nM A $\beta$ vs. 200 nM A $\beta, P<0.0001$. (I,J) siGpc4/overGpc4 lentivirus was injected into both lateral ventricles and the hippocampus of 4-month-old (APP/PS1) mice. Two months after lentivirus injection, mice were sacrificed for Thioflavin staining. $\beta$-amyloid plaques were stained in green. All particles were counted and compared against those in the hippocampus. NSCs, neural stem cells; Gpc4, glypican 4; AdV, adenovirus; DAPI, 4',6-diamidino-2-phenylindole; ELISA, enzyme-linked immunosorbent assay.

showed a higher uptake of $A \beta$ compared to the other groups (Figure 2F).

\section{A $\beta$ Upregulates Gpc4 Expression in NSCs}

To identify the role of Gpc4 in NSCs in AD, we examined Gpc4 expression patterns in NSCs. Gpc4 (green) colocalized with cells positive for Ki67 or nestin (red), which proves the expression of Gpc4 in NSCs. Gpc4 was widely expressed in NSCs. Double-positive Gpc4/Ki67 represents NSCs undergoing cell division (Figure 3A, yellow arrow). We also observed some Gpc4-negative Ki67-positive NSCs (red arrow) and Gpc4-positive Ki67-negative NSCs (green arrow). Furthermore, 
A

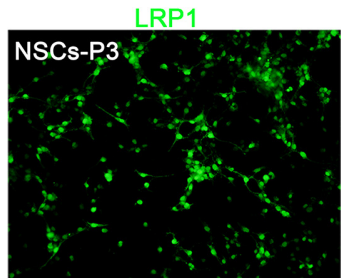

DAPI
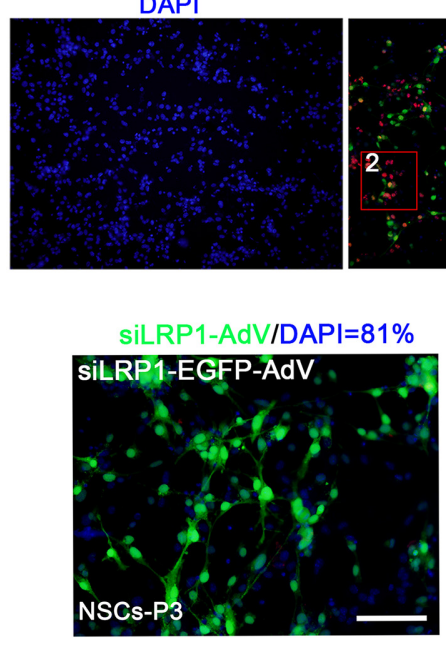

B
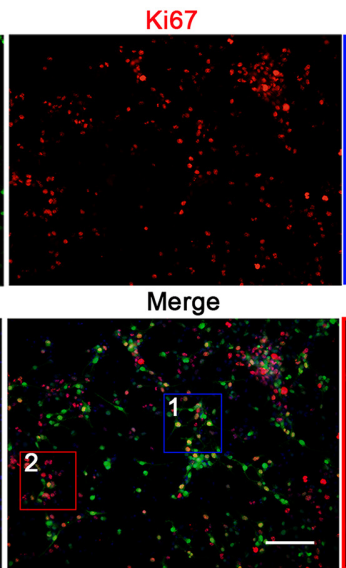

Magnified

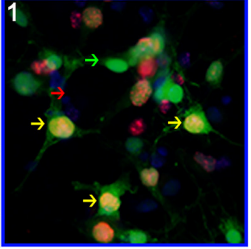

Magnified

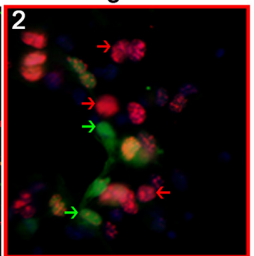

C
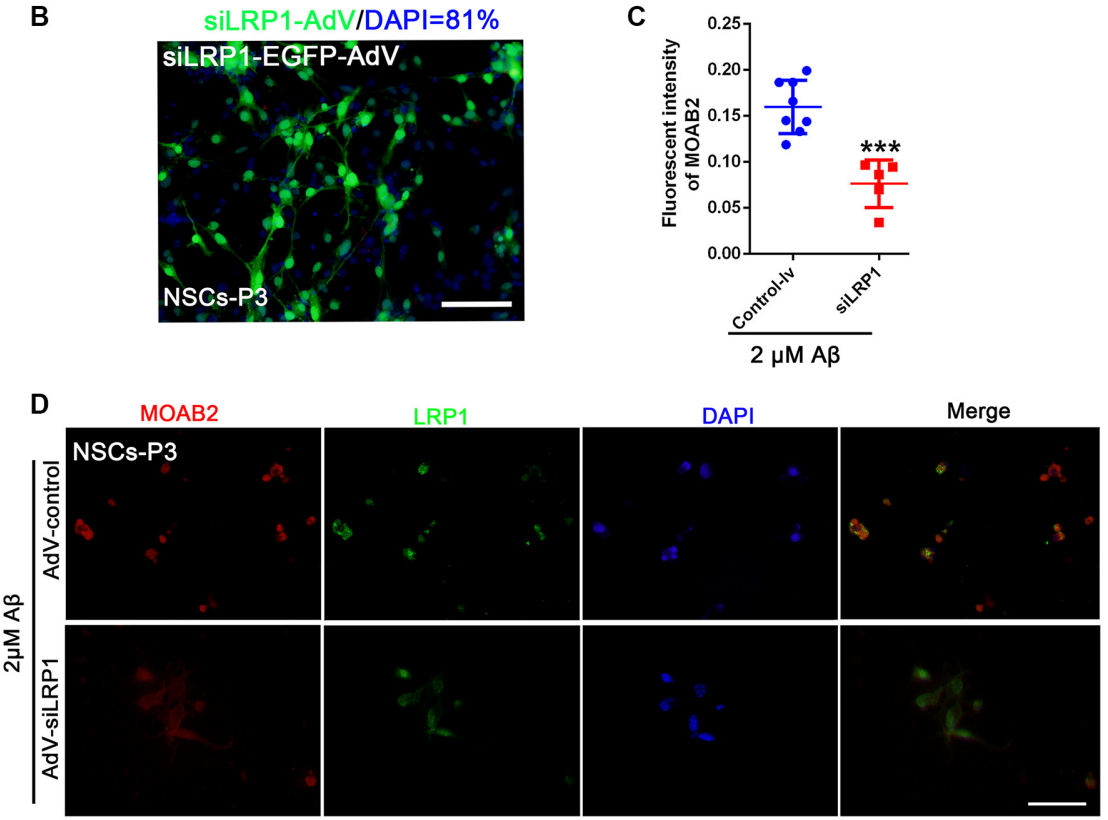

FIGURE 5 | LRP1 is expressed in NSC and regulates the internalization of A . (A) Immunofluorescence analysis revealing the expression of LRP1 (green) with Ki67 (red) in NSCs. Nuclei were counterstained with DAPI (blue). LRP1 was widely expressed in NSCs (green). Double positive LRP1/Ki67 (yellow arrow), LRP1-negative Ki67-positive NSCs (red arrow), and LRP1-positive Ki67-negative NSCs (green arrow) were also observed. Scale bar $=50 \mu \mathrm{m}$. (B) NSCs were plated in complete medium, and then siLRP1 adenovirus expression using enhanced green fluorescent protein (green) was added $\left(2 \times 10^{12}\right)$ for $24 \mathrm{~h}$ for transfection. The medium was then changed for $48 \mathrm{~h}$. Nuclei were marked with DAPI (blue). The ratio of adenovirus transfection was calculated. (C,D) NSCs were plated in complete medium, and then control-lentivirus and siLRP1 lentivirus were added $24 \mathrm{~h}$ for transfection. The medium was then changed for $48 \mathrm{~h}$. Twelve hours after adding $2 \mu \mathrm{M} A \beta$, fluorescence intensities of MOAB2 and LRP1 were measured and compared. ${ }^{* * \star}$ represents siLRP1+ $2 \mu \mathrm{M} A \beta$ vs. $2 \mu \mathrm{M} A \beta, P<0.0001$. LRP1, low-density lipoprotein receptor-related protein 1; NSCs, neural stem cells; DAPI, 4',6-diamidino-2-phenylindole.

we assessed whether the expression of Gpc4 was regulated by $\mathrm{A} \beta$ treatment. NSCs were incubated with $200 \mathrm{nM}$ and $2 \mu \mathrm{M}$ $\mathrm{A} \beta$ for $12 \mathrm{~h}$. Our results from immunofluorescence staining and western blotting illustrated that Gpc4 expression increased with $\mathrm{A} \beta$ concentration (Figures $3 \mathrm{~B}-\mathrm{D}$ ).

\section{Gpc4 Regulates NSC Uptake of A}

Co-IP was performed to detect the relationship between Gpc4 and $A \beta$. We found that Gpc4 forms a protein complex with $\mathrm{A} \beta$ in the APP/PS1 mouse brain (Figure 4A). To further determine the role of Gpc4 in $A \beta$ internalization, $A d V$ and lentivirus were used to either overexpress or attenuate Gpc4 expression in NSCs and APP/PS1 mice, respectively. The AdV transfection ratio was $72 \%$ for siGpc4-AdV and $70 \%$ for overGpc4-AdV (Figure 4B). The timing for the experimental procedure of Gpc4 and LRP1 AdV and $A \beta$ treatment is laid out in Figure 4C. Furthermore, cy3-A $\beta$ (200 nM and 2 $\mu \mathrm{M}$ ) was added to siGpc4-AdV-, Gpc4-AdV-, or control-AdV- 
infected NSCs for $6 \mathrm{~h}$. Subsequently, the A $\beta$ particles per cell were counted. Attenuating Gpc4 decreased the number of $A \beta$ particles in the $200 \mathrm{nM}$ and $2 \mu \mathrm{M}$ groups. Overexpression of Gpc4 was able to upregulate the $A \beta$ particle number in the $200 \mathrm{nM}$ group but had no significant effect in the $2 \mu \mathrm{M}$ group (Figures 4D,E).

Next, cells were monitored to detect whether Gpc4 induced $\mathrm{A} \beta$ production. No significant differences were observed between the siGpc4 and overGpc4 adenovirus groups (Figure 4F). overGpc4 had no significant effect on $2 \mu \mathrm{M}$ A $\beta$ internalization, but siGpc4 significantly attenuated the internalized $A \beta$ level (Figure 4G). In the $200 \mathrm{nM} \mathrm{A} \beta$-treated group, overGpc4-AdV increased NSC A $\beta$ internalization, but siGpc4-AdV had no significant effect on blocking $A \beta$ internalization (Figure $4 \mathbf{H}$ ). siGpc4/overGpc4 lentivirus were injected into the hippocampus of 4-month old (APP/PS1) mice brains, and 2 months after injection, mice were sacrificed for $S$-plaque detection. $A \beta$ plaques were stained using Thioflavin staining. Plaque numbers in the siGpc4 and overGpc4 groups did not change at this stage in APP/PS1 mice (Figures 4I,J). These results suggest an important dose-dependent effect of Gpc4 on A $\beta$ internalization in NSCs at the early stage of AD.

\section{LRP1 Is Expressed in NSCs and Regulates the $A \beta$ Internalization}

LRP1 is an A $\beta$ receptor that plays a role in Gpc4-induced $\mathrm{A} \beta$ internalization. We first identified the expression of LRP1 in NSCs by double staining NSCs with Ki67 and LRP1. LRP1 colocalized with Ki67-positive cells (Figure 5A). Doublepositive LRP1/Ki67 (yellow arrow), LRP1-negative Ki67-positive (red arrow), and LRP1-positive Ki67-negative NSCs (green arrow) were all observed (Figure 5A). Moreover, the transfection ratio of siLRP1 was $81 \%$ (Figure $5 B$. The effect of LRP1 on A $\beta$ internalization was analyzed by double staining of LRP1 with the $A \beta$ antibody MOAB2 in AdV control and AdV-siLRP1treated groups. siLRP1 remarkably decreased $A \beta$ levels in NSCs (Figures 5C,D), suggesting LRP1 is responsible for $A \beta$ transportation in NSCs. However, the relationship between LRP1 and Gpc4 remains unclear.

\section{Gpc4 Regulates A $\beta$ Internalization Partially via LRP1 in NSCs}

To more precisely define the relationship between Gpc4 and LRP1, co-IP was performed on the cell lysis of APP/PS1 mice. Gpc4 was able to bind to LRP1, forming a protein complex in the brains of $\mathrm{AD}$ mice (Figures 6A,B). These observations suggest that LRP1 plays a role in Gpc4-induced $A \beta$ internalization.

We next aimed to reveal the action of Gpc4 and LRP1 in $\mathrm{A} \beta$ internalization. NSCs were transfected with control, siLRP1, siLRP1+siGpc4, and siLRP1+overGpc4 AdV for 3 days, and then $A \beta$ was added for $6 \mathrm{~h}$ before cells were harvested for ELISA. siLRP1 remarkably decreased $A \beta$ uptake by NSCs. In the siLRP1 and siGpc4 groups, the amount of internalized $A \beta$ was much less compared to the siLRP1-treated group. Furthermore, in the siLRP1+overGpc4-treated group, the internalized $A \beta$ level was increased compared to the siLRP1+siGpc4 group (Figure 6C).

\section{Gpc4 Regulates Cell Apoptosis via LRP1 in NSCs}

Control, siLRP1, overGpc4, and overGpc4+siLRP1 AdV were transfected into NSCs for 3 days, and then $\mathrm{A} \beta$ was added for $12 \mathrm{~h}$. The JC-1 kit was used to detect the MMP in NSCs. JC-1 monomers (green) and aggregates (red) were compared and normalized to those of the control group. In $2 \mu \mathrm{M}$ A $\beta$ experiments, JC-1, TUNEL, and western blotting were used to determine whether Gpc4/LRP1 regulates the toxic effect of $A \beta$ on NSCs. siLRP1 significantly decreased the ratio of JC-1 monomers/aggregates compared to the control group. Moreover, overGpc4 increased MMP damage compared to siLRP1. overGpc4+siLRP1 significantly increased the MMP compared to siLRP1; however, the MMP damage in the overGpc4+siLRP1 group was lower than that in the overGpc4 group (Figures 7A,B). Moreover, the level of Cytc was decreased in the siLRP1 and siLRP1+siGpc4 groups, and higher in the siLRP1+overGpc4 group (Figure 7C). Furthermore, TUNEL staining was used to detect whether Gpc4 and LRP1 regulate A $\beta$-induced cell death. Compared to the control group, siLRP1 attenuated NSC apoptosis while overGpc4 increased it. siLRP1 decreased the effect caused by overGpc4 (Figures 7D,E). The expression of Bax was also detected using western blotting, which is consistent with the results of TUNEL staining (Figures 7D-F).

In $200 \mathrm{nM} \mathrm{A} \beta$ experiments, JC- 1 and TUNEL assays were used to determine whether Gpc4 induces toxic effects by enriching the nontoxic effect of $\mathrm{A} \beta$ on NSCs. Initially, $200 \mathrm{nM}$ $\mathrm{A} \beta$ had no toxic effect on NSCs, but overGpc4 in $200 \mathrm{nM}$ $\mathrm{A} \beta$-treated NSCs increased MMP damage (Figures 8A,B). Furthermore, TUNEL staining was used to detect whether Gpc4/LRP1 regulated $A \beta$-induced cell death. No significant changes were observed among the four groups (Figures 8C,D).

\section{DISCUSSION}

The dysregulation of adult neurogenesis in $\mathrm{AD}$ occurs at an early stage of the disease and the mechanism has not been completely elucidated (Boese et al., 2020). Heparan sulfate proteoglycan, a highly conserved protein expressed in many species and tissues, is involved in basic cellular processes, such as cell proliferation, cell growth, axon guidance, and synapse formation (Rawson et al., 2005; Stewart and Sanderson, 2014; Jiao et al., 2016; Condomitti and de Wit, 2018), and is highly related to $\mathrm{AD}$ pathology. Twenty years ago, Gpc4, a heparan sulfate proteoglycan, was reported to be increased in the brains of $\mathrm{AD}$ patients and was initially found to be responsible for neurogenesis (Gysi et al., 2013; Blanchette et al., 2015; Zhang et al., 2015). This suggests that abnormal expression of Gpc4 in $\mathrm{AD}$ patients may contribute to NSC damage. We confirmed that Gpc4 is highly expressed in NSCs (Luxardi et al., 2007; Yu et al., 2017). Gpc4 expression was significantly higher in A $\beta$-treated NSCs than in control group NSCs. Gpc4 also regulated the internalization of $\mathrm{A} \beta$ by NSCs and enriched low concentrations of $A \beta$ into NSCs. The overexpression of Gpc4 suggests that it may play a role in $\mathrm{A} \beta$-induced toxicity in NSCs. 


\section{A}
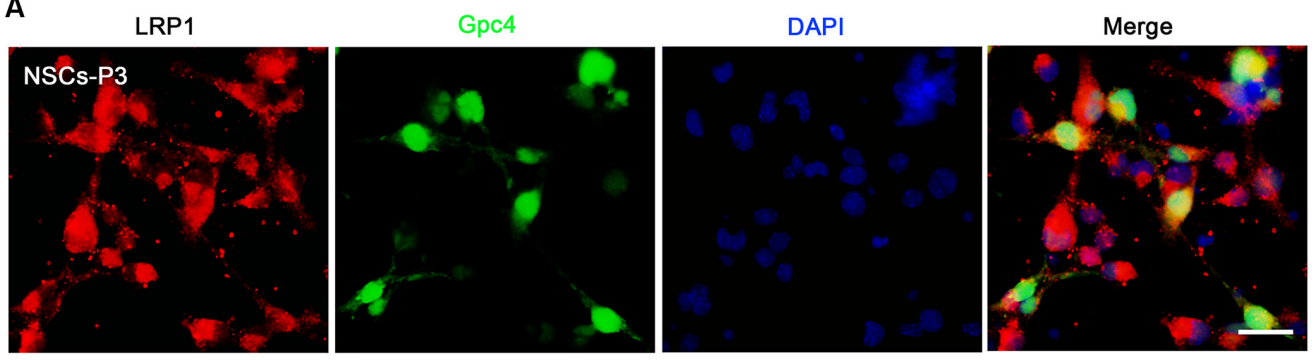

B

wt T

C
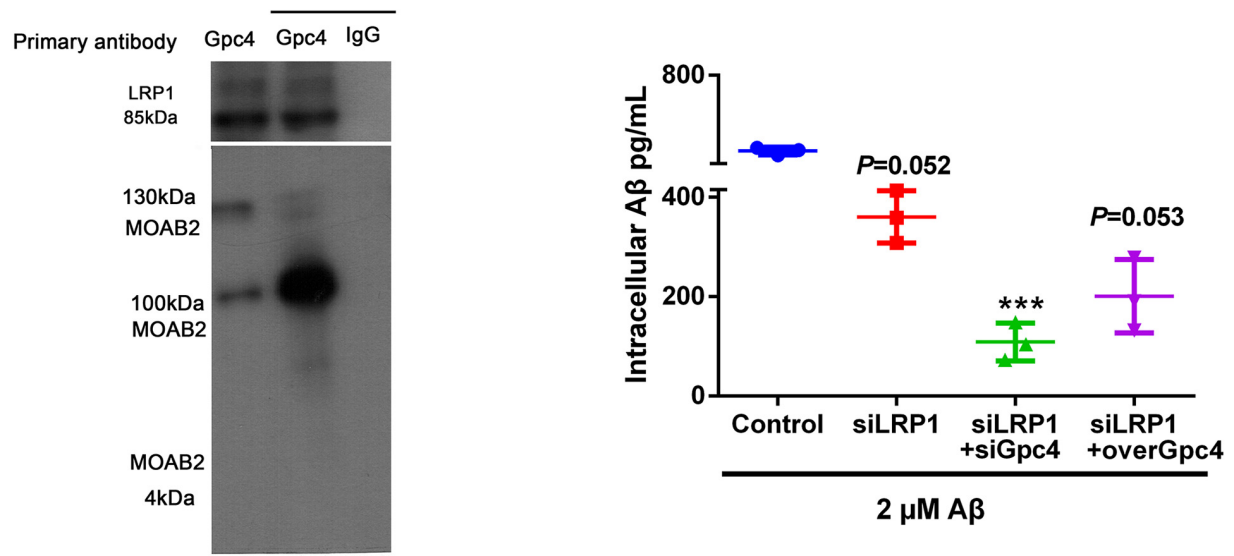

$2 \mu \mathrm{MA}$

FIGURE 6 | Gpc4 regulates A $\beta$ internalization partially via LRP1 in NSCs. (A) Immunofluorescence revealed LRP1 (red) abundantly colocalized with Gpc4 (green) in NSCs. Nuclei were counterstained with DAPI (blue), scale bar = $20 \mu \mathrm{m}$. (B) Co-immunoprecipitation result from protein lysis extracted from 6-month-old APP/PS1 mice. Protein samples were incubated with primary antibody Gpc4. Protein complexes able to bind to Gpc4 were then eluted. Western blotting was used to detect the MOAB2- (A 342$)$ and LRP1-positive binds. (C) Seventy-two hours after adenovirus transfection, $2 \mu \mathrm{M}$ A $\beta 42$ was added to the control, siLRP1, siLRP1+siGpc4, and siLRP1+overGpc4 groups. The levels of A 342 were detected using ELISA. ${ }^{\star \star \star}$ represents siLRP1+ $2 \mu M A \beta$ vs. siGpc4+siLRP1+ $2 \mu M$ A $\beta, P=0.0011$. GPc4, glypican 4; LRP1, low-density lipoprotein receptor related protein 1; NSCs, neural stem cells; DAPI, 4',6-diamidino-2-phenylindole; ELISA, enzyme-linked immunosorbent assay.

Heparan sulfate proteoglycans have been proposed to be responsible for $A \beta$ enrichment. We found that Gpc4 expression was increased in A $\beta$-treated NSCs in a concentration-dependent manner. Nevertheless, considering neurogenesis deficiency is an important aspect of memory loss, Gpc4 may regulate $A \beta$ enrichment in NSCs. The average concentration of $A \beta 42$ in the brain white matter of patients with $\mathrm{AD}$ is $60 \mathrm{pM} / \mathrm{L}$ (Collins-Praino et al., 2014; Fu et al., 2016). While the concentration of $A \beta$ in the brain extracellular fluid, such as the interstitial fluid and cerebrospinal fluid, is low $\left(10^{-10}-10^{-9}\right.$ M; Ma and Qian, 2019), in vitro studies have suggested that the critical concentration for spontaneous aggregation of $\mathrm{A} \beta$ is in the $\mu \mathrm{M}$ range. Therefore, $\mathrm{A} \beta$ concentrations in vivo would have to be increased by at least three orders of magnitude for spontaneous aggregation. Several mechanisms have been proposed to explain this large concentration gap. The most likely hypotheses are that the concentration could be increased through membrane association (Gorbenko and Kinnunen, 2006; Aisenbrey et al., 2008) or macromolecular crowding (Munishkina et al., 2004; Hu et al., 2009; FernandezPerez et al., 2020; Wang et al., 2020; Wu et al., 2020).
However, the mechanism underlying $A \beta$ enrichment in NSCs remains unknown.

The role of Gpc4 in regulating different concentrations of $A \beta$ internalization in NSCs is A $\beta$ dose-dependent. siGpc4 decreased NSC uptake of $2 \mu \mathrm{M} \mathrm{A} \beta$, and overGpc4 increased NSC uptake of $200 \mathrm{nM} \mathrm{A} \beta$. This different role of Gpc4 on $2 \mu \mathrm{M} \mathrm{A} \beta$ and $200 \mathrm{nM} \mathrm{A} \beta$ transportation indicates that Gpc4 is functional at nanomolar $\mathrm{A} \beta$ concentrations; however, the transportation efficiency of Gpc4 reaches its saturation point at micromolar $A \beta$ concentrations. Gpc4 is a key regulator of $A \beta$ enrichment at nanomolar concentrations of $A \beta$. This illustrates why siGpc4 lentivirus had no effect on $\beta$-amyloid plaque numbers. Therefore, Gpc4 is a key regulator of $A \beta$ enrichment during the early stages of $\mathrm{AD}$, but not in the later stages.

Heparan sulfate, the extracellular portion of Gpc4, has a high affinity for $A \beta$ and its receptors (Yamada and Hamaguchi, 2018; Du et al., 2020). Thus, heparan sulfate on Gpc4 may play a role in regulating $A \beta$ internalization. Heparan sulfate also has a high affinity for LRP1 and the cellular prion protein (Taylor et al., 2009; Gao et al., 2019; Hu et al., 2019), which are also key receptors for $A \beta$ transportation. This suggests that Gpc4 may 
A

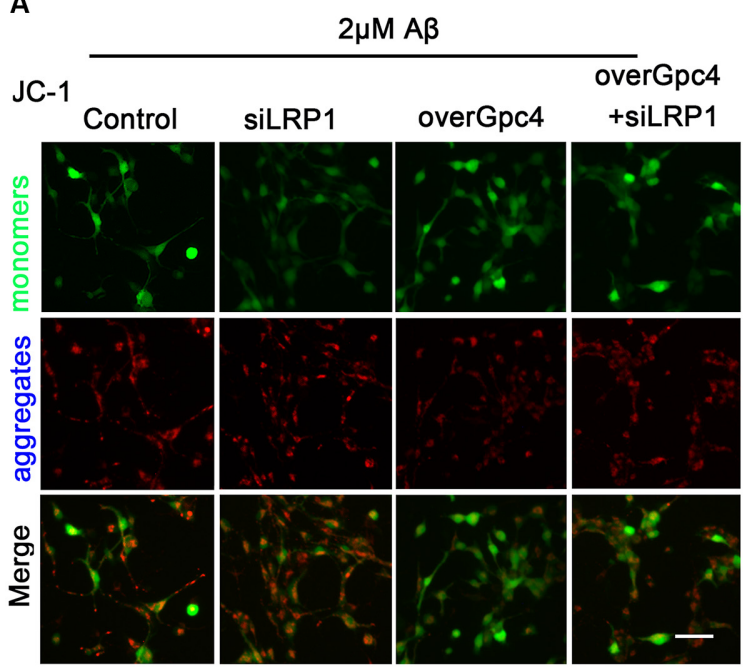

D

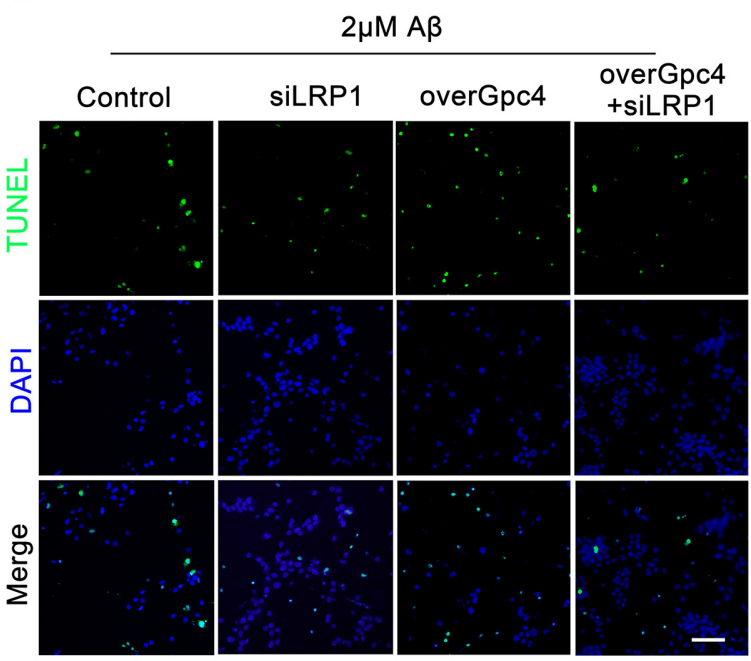

B
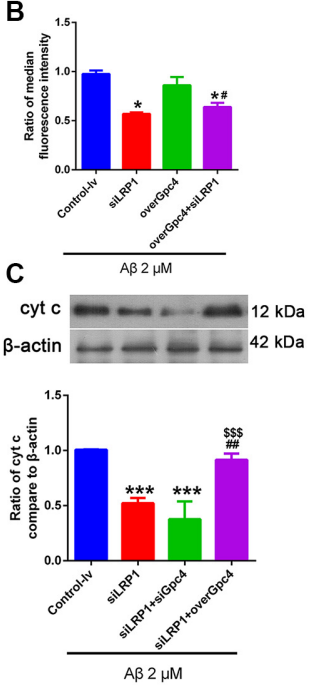

E

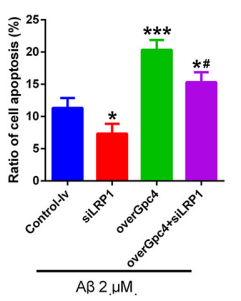

$\mathbf{F}$
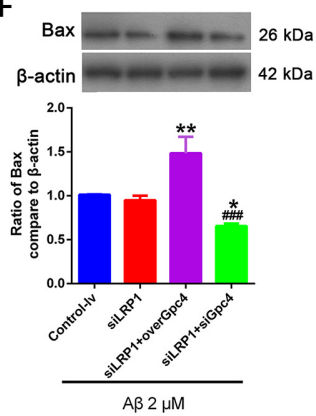

FIGURE 7 | Gpc4 regulates cell apoptosis partly via LRP1 in NSCs. (A,B) NSCs were infected with control, siLRP1, overGpc4, and overGpc4+siLRP1 AdV for 3 days, and $2 \mu \mathrm{M}$ A $\beta$ was added for $12 \mathrm{~h}$. The JC- 1 kit was used to detect the mitochondrial membrane potential in NSCs. JC-1 monomers (green) and aggregates (red) were compared and normalized to the control group. The ratio of monomers to aggregates was calculated. (C) Seventy-two hours after AdV infection, $2 \mu \mathrm{M}$ A 42 was added to the control, siLRP1, siLRP1+siGpc4, and siLRP1+overGpc4. The levels of Cytc were determined using western blotting. ${ }^{\star \star \star}$ represents silRP1+siGpc4 vs. control, $P=0.0001$, siLRP1 vs. control, $P=0.0007$; siLRP1+overGpc4 vs. siLRP1, $P=0.0028$. $\$ \$$ siLRP1+siGpc4 vs. silRP1+overGpc4, $P=0.0252$, *siLRP1+siGpc4 vs. silRP1+overGpc4, $P=0.0003$. (D,E) NSCs were infected with control, silRP1, overGpc4, and overGpc4+siLRP1 AdV for 3 days, and $A \beta$ was added for $12 \mathrm{~h}$. TUNEL staining was used to detect whether Gpc4 regulated A $\beta$-induced cell death via LRP1. The ratio of apoptotic cells was calculated based on TUNEL positive cells (green) and DAPI (blue). (F) The expression of Bax was also detected using western blotting, ${ }^{* *}$ represents siLRP1+overGpc4 vs. siLRP1, $P=0.0007$, "silRP1+siGpc4 vs. silRP1, $P=0.0252$, *siLRP1+siGpc4 vs. siLRP1+ overGpc4, $P$ < 0.0001. GPc4, glypican 4; LRP1, low-density lipoprotein receptor related protein 1; NSCs, neural stem cells; DAPI, 4',6-diamidino-2-phenylindole; AdV, adenovirus; TUNEL, terminal deoxynucleotidyl transferase dUPT nick end labeling.

gather the receptor and $\mathrm{A} \beta$ to the cell surface during the early stage of $\mathrm{AD}$. However, the relationship between Gpc4 and the classic $A \beta$ receptor LRP1 is yet to be determined.

LRP1 is an important receptor for the induction of $A \beta$ internalization in astrocytes. Previous studies have shown that LRP1 clears $73.8 \%$ of $\mathrm{A} \beta$ injected into the brain towards blood circulation through the blood-brain barrier (Ma et al., 2018; Van Gool et al., 2019). Through the LRP1-related pathway, $A \beta$ is internalized by neurons and localized in lysosomes, endosomes, and mitochondria, with little recycling (Lillis et al., 2005). ApoE lipid rafts (GilatFrenkel et al., 2014; Rushworth and Megson, 2014), the 
A
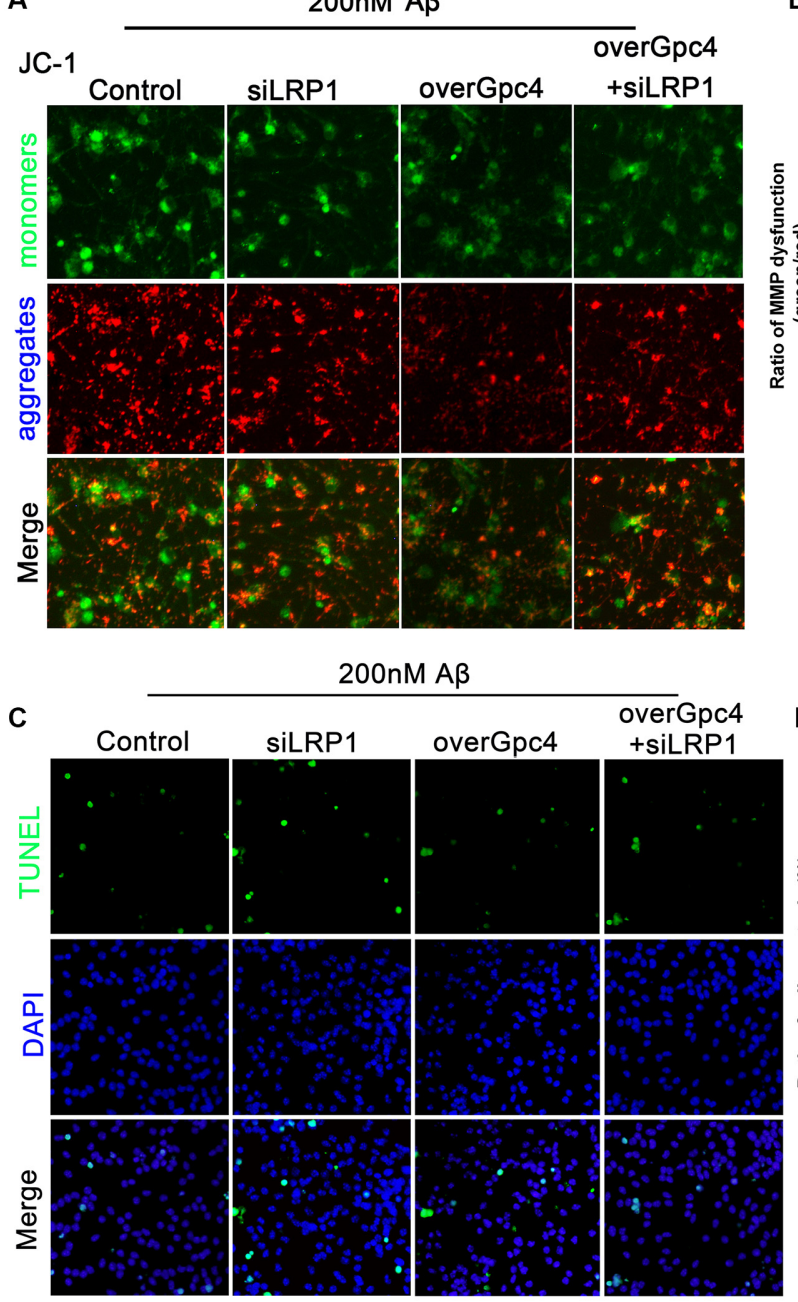

B
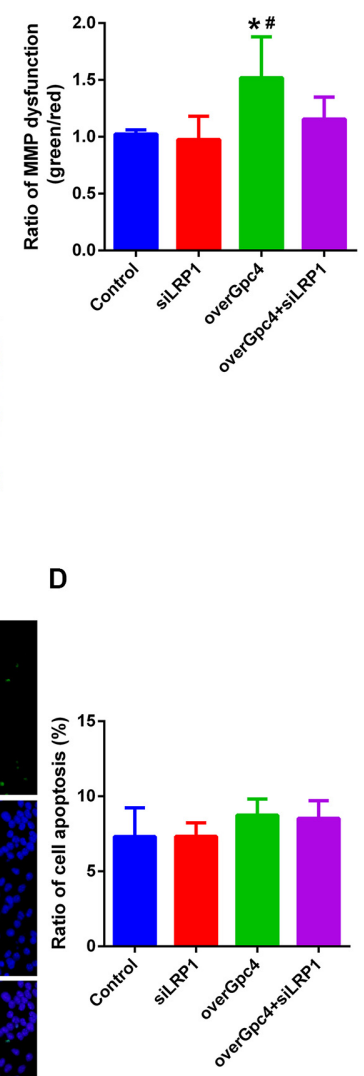

FIGURE 8 | Role of Gpc4 and LRP1 on 200 nM A $\beta$ on NSCs. (A,B) NSCs were infected with control, siLRP1, overGpc4, and overGpc4+siLRP1 AdV for 3 days, and then $200 \mathrm{nM} \mathrm{A} \beta$ was added for $12 \mathrm{~h}$. The JC-1 kit was used to detect the mitochondrial membrane potential in NSCs. JC-1 monomers (green) and aggregates (red) were compared and normalized to those of the control group. The ratio of monomers/aggregates was calculated. * represents overGpc 4 vs. control, $P=$ 0.0036, " represents overGpc4 vs. siLRP1, $P=0.0080$. (C,D) NSCs were infected with control, silRP1, overGpc4, and overGpc4+siLRP1 AdV for 3 days, and 200 $\mathrm{nM} A \beta$ was added for $12 \mathrm{~h}$. TUNEL staining was used to detect whether Gpc4 regulated the A $\beta$-induced cell death via LRP1. The ratio of apoptotic cells was calculated based on TUNEL positive cells (green) and DAPI (blue). NSCs, neural stem cells; GPc4, glypican 4; LRP1, low-density lipoprotein receptor related protein 1; AdV, adenovirus; TUNEL, terminal deoxynucleotidyl transferase dUPT nick end labeling; DAPI, 4',6-diamidino-2-phenylindole.

ERK1/2 pathway, Wnt3a, JNK, and other heparan sulfate proteoglycans may also play a role in $A \beta$ internalization (Lai et al., 2010; Shi et al., 2011; Li et al., 2019; Mii and Takada, 2020). First, decreased LRP1 allowed more ApoE4-coated $\mathrm{A} \beta$ to pass through the NSC membrane via Gpc4 overexpression, leading to an upregulation of intracellular $\mathrm{A} \beta$ levels. Second, ERK1/2, as the downstream target of both LRP1 and Gpc4, may also regulate the expression of other $\mathrm{A} \beta$ receptors. siLRP1 decreased the expression of ERK1/2; however, Gpc4 overexpression activated ERK1/2, subsequently activating other receptors related to $A \beta$ internalization. Lastly, Gpc4 is responsible for many cellular growth processes, such as cell division and cell metabolism (Farhy-Tselnicker et al., 2017; McGough and Vecchia, 2020). It is possible that overGpc4+siLRP1 may activate these processes and therefore upregulate $A \beta$ transportation.

We have previously shown that internalized $A \beta$ is transported into the mitochondria in vitro and in vivo (Yang et al., 2015; Ma et al., 2016, 2018). In this study, we found that Gpc4 regulates mitochondrial dysfunction and cell apoptosis in NSCs partly via LRP1. We used the JC-1 kit to detect the role of internalized $A \beta$ on MMP, which is also called mitochondrial depolarization. We found that in toxic $A \beta$-treated groups, attenuating Gpc4/LRP1 expression decreased intracellular $A \beta$, MMP damage, and NSC apoptosis. In the physical A $\beta$-treated groups, Gpc4 overexpression caused MMP damage but had no 
effect on cell apoptosis. These results indicate that internalized $\mathrm{A} \beta$ is harmful to both mitochondrial function and cell viability.

\section{CONCLUSION}

We demonstrated that $\mathrm{Gpc} 4$ regulates $\mathrm{A} \beta$ internalization at an early stage of $\mathrm{AD}$. This process is dose-dependent, and occurs partly via the well-known A $\beta$ receptor, LRP1. However, many questions remain unanswered. Heparan sulfate on the extracellular surface of Gpc4 is important for receiving and binding to $\mathrm{A} \beta$ and its receptors. Gpc4 was initially reported to have a major effect on synapse formation and neurogenesis; therefore, it is also important to determine whether Gpc4 mediates NSC-derived neurogenesis by regulating A $\beta$ internalization in NSCs.

\section{DATA AVAILABILITY STATEMENT}

The original contributions presented in the study are included in the article, further inquiries can be directed to the corresponding author.

\section{ETHICS STATEMENT}

The animal study was reviewed and approved by Institutional Animal Care and Use Committee at Xi' an Jiaotong University.

\section{REFERENCES}

Aisenbrey, C., Borowik, T., Byström, R., Bokvist, M., Lindström, F., Misiak, H., et al. (2008). How is protein aggregation in amyloidogenic diseases modulated by biological membranes. Eur. Biophys. J. 37, 247-255. doi: 10.1007/s00249007-0237-0

Blanchette, C. R., Perrat, P. N., Thackeray, A., and Bénard, C. Y. (2015). Glypican is a modulator of netrin-mediated axon guidance. PLoS Biol. 13:e1002183. doi: 10.1371/journal.pbio.1002183

Bloom, G. S. (2014). Amyloid- $\beta$ and tau: the trigger and bullet in Alzheimer disease pathogenesis. JAMA Neurol. 71, 505-508. doi: 10.1001/jamaneurol.2013.5847

Boese, A. C., Hamblin, M. H., and Lee, J. P. (2020). Neural stem cell therapy for neurovascular injury in Alzheimer's disease. Exp. Neurol. 324:113112. doi: 10.1016/j.expneurol.2019.113112

Collins-Praino, L. E., Francis, Y. I., Griffith, E.Y., Wiegman, A. F., Urbach, J., Lawton, A., et al. (2014). Soluble amyloid beta levels are elevated in the white matter of Alzheimer's patients, independent of cortical plaque severity. Acta Neuropathol. Commun. 2:83. doi: 10.1186/s40478-014-0083-0

Condomitti, G., and de Wit, J. (2018). Heparan sulfate proteoglycans as emerging players in synaptic specificity. Front. Mol. Neurosci. 11:14. doi: 10.3389/fnmol. 2018.00014

Du, Y. Y., Liu, X. L., Zhu, X. L., Liu, Y., Wang, X. R., and Wu, X. P. (2020). Activating transcription factor 6 reduces A beta 1-42 and restores memory in Alzheimer's disease model mice. Int. J. Neurosci. 130, 1015-1023. doi: 10.1080/00207454.2020.1715977

Farhy-Tselnicker, I., van Casteren, A. C. M., Lee, A., Chang, V. T., Aricescu, A. R., and Allen, N. J. (2017). Astrocyte-Secreted glypican 4 regulates release of neuronal pentraxin 1 from axons to induce functional synapse formation. Neuron 96, 428-445.e13. doi: 10.1016/j.neuron.2017.09.053

Fernandez-Perez, E. J., Gallegos, S., Armijo-Weingart, L., Araya, A., RiffoLepe, N. O., Cayuman, F., et al. (2020). Changes in neuronal excitability and synaptic transmission in nucleus accumbens in a transgenic Alzheimer's disease mouse model. Sci. Rep. 10:19606. doi: 10.1038/s41598-020-76456-w

\section{AUTHOR CONTRIBUTIONS}

KM performed most of the experiments, analyzed data, and wrote the rough draft. SX performed experiments, data analysis, and redrafting. YLu and YiLi performed NSCs cell culture. CZ performed the animal housing. ZZ and YF took part in the virus infection experiment. $\mathrm{ZZ}$ and YoLi participated in the experiment design. $\mathrm{XC}$ designed the research and finalized the manuscript. All authors contributed to the article and approved the submitted version.

\section{FUNDING}

This work was supported by grants from the National Natural Science Foundation of China, NSFC (No. 82001493 and No. 81901156); the China Postdoctoral Science Foundation (No. 2019M653662); Natural Science Basic Research Program of Shaanxi (No. 2021JQ-881); and Scientific Research Program Funded by Shaanxi Provincial Education Department (No. 20JK0958).

\section{ACKNOWLEDGMENTS}

We sincerely thank Prof. Wei-Na Yang for her generous sharing of the $\mathrm{AD}$ transgenetic mice used in this experiment.

Fu, Y., Zhao, J., Atagi, Y., Nielsen, H. M., Liu, C. C., Zheng, H., et al. (2016). Apolipoprotein E lipoprotein particles inhibit amyloid- $\beta$ uptake through cell surface heparan sulphate proteoglycan. Mol. Neurodegener. 11:37. doi: 10.1186/s13024-016-0099-y

Gao, Y. L., Liu, Q., Xu, L. L., Zheng, N., He, X. M., and Xu, F. Q. (2019). Imaging and spectral characteristics of amyloid plaque autofluorescence in brain slices from the APP/PS1 mouse model of Alzheimer's disease. Neurosci. Bull. 35, 1126-1137. doi: 10.1007/s12264-019-00393-6

Ghazale, H., Ramadan, N., Mantash, S., Zibara, K., El-Sitt, S., Darwish, H., et al. (2018). Docosahexaenoic acid (DHA) enhances the therapeutic potential of neonatal neural stem cell transplantation post-traumatic brain injury. Behav. Brain Res. 340, 1-13. doi: 10.1016/j.bbr.2017.11.007

Gilat-Frenkel, M., Boehm-Cagan, A., Liraz, O., Xian, X., Herz, J., and Michaelson, D. M. (2014). Involvement of the Apoer2 and Lrp1 receptors in mediating the pathological effects of ApoE4 in vivo. Curr. Alzheimer Res. 11, 549-557. doi: 10.2174/1567205010666131119232444

Gorbenko, G. P., and Kinnunen, P. K. (2006). The role of lipid-protein interactions in amyloid-type protein fibril formation. Chem. Phys. Lipids 141, 72-82. doi: 10.1016/j.chemphyslip.2006.02.006

Gysi, S., Rhiner, C., Flibotte, S., Moerman, D. G., and Hengartner, M. O. (2013) A network of HSPG core proteins and HS modifying enzymes regulates netrindependent guidance of D-type motor neurons in Caenorhabditis elegans. PLoS One 8:e74908. doi: 10.1371/journal.pone.0074908

Hu, X., Crick, S. L., Bu, G., Frieden, C., Pappu, R. V., and Lee, J. M. (2009). Amyloid seeds formed by cellular uptake, concentration and aggregation of the amyloid-beta peptide. Proc. Natl. Acad. Sci. U S A 106, 20324-20329. doi: 10.1073/pnas.0911281106

Hu, Y. R., Xing, S. L., Chen, C., Shen, D. Z., and Chen, J. L. (2019). Tiaoxin Recipe, a Chinese herbal formula, inhibits microRNA-34a expression in the APPswe/PS1 Delta E9 mouse model of Alzheimer's disease. J. Integr. Medicine 17, 404-409. doi: 10.1016/j.joim.2019.09.002

Huang, D., Cao, Y., Yang, X., Liu, Y., Zhang, Y., Li, C., et al. (2021). A nanoformulation-mediated multifunctional stem cell therapy with improved 
beta-amyloid clearance and neural regeneration for alzheimer's disease. Adv. Mater 33:e2006357. doi: 10.1002/adma.202006357

Jiao, Q., Wang, L., Zhang, Z. C., Wang, Y. Y., Yan, H. Q., Ma, W., et al. (2016). Dynamic expression of srGAP2 in cell nuclei and cytoplasm during the differentiation of rat neural stem cells in vitro. Mol. Med. Rep. 14, 4599-4605. doi: 10.3892/mmr.2016.5795

Lai, J. P., Sandhu, D. S., Yu, C., Moser, C. D., Hu, C., Shire, A. M., et al. (2010). Sulfatase 2 protects hepatocellular carcinoma cells against apoptosis induced by the PI3K inhibitor LY294002 and ERK and JNK kinase inhibitors. Liver Int. 30, 1522-1528. doi: 10.1111/j.1478-3231.2010.02336.x

Li, N., Wei, L., Liu, X., Bai, H., Ye, Y., Li, D., et al. (2019). A frizzled-like cysteine-rich domain in glypican-3 mediates wnt binding and regulates hepatocellular carcinoma tumor growth in mice. Hepatology 70, 1231-1245. doi: 10.1002/hep.30646

Lillis, A. P., Mikhailenko, I., and Strickland, D. K. (2005). Beyond endocytosis: LRP function in cell migration, proliferation and vascular permeability. J. Thromb. Haemost. 3, 1884-1893. doi: 10.1111/j.1538-7836.2005.01371.x

Liu, C. C., Liu, C. C., Kanekiyo, T., Xu, H., and Bu, G. (2013). Apolipoprotein E and Alzheimer disease: risk, mechanisms and therapy. Nat. Rev. Neurol. 9, 106-118. doi: 10.1038/nrneurol.2012.263

Liu, C. C., Zhao, N., Yamaguchi, Y., Cirrito, J. R., Kanekiyo, T., Holtzman, D. M., et al. (2016). Neuronal heparan sulfates promote amyloid pathology by modulating brain amyloid- $\beta$ clearance and aggregation in Alzheimer's disease. Sci. Transl. Med. 8:332ra344. doi: 10.1126/scitranslmed. $\operatorname{aad} 3650$

Luxardi, G., Galli, A., Forlani, S., Lawson, K., Maina, F., and Dono, R. (2007). Glypicans are differentially expressed during patterning and neurogenesis of early mouse brain. Biochem. Biophys. Res. Commun. 352, 55-60. doi: 10.1016/j. bbrc.2006.10.185

Ma, K. G., Lv, J., Hu, X. D., Shi, L. L., Chang, K. W., Chen, X. L., et al. (2016). The p38 mitogen-activated protein kinase signaling pathway is involved in regulating low-density lipoprotein receptor-related protein 1-mediated $\beta$ amyloid protein internalization in mouse brain. Int. J. Biochem. Cell Biol. 76, 75-86. doi: 10.1016/j.biocel.2016.04.019

Ma, K. G., Lv, J., Yang, W. N., Chang, K. W., Hu, X. D., Shi, L. L., et al. (2018). The p38 mitogen activated protein kinase regulates $\beta$-amyloid protein internalization through the $\alpha 7$ nicotinic acetylcholine receptor in mouse brain. Brain Res. Bull. 137, 41-52. doi: 10.1016/j.brainresbull.2017.11.006

Ma, K. G., and Qian, Y. H. (2019). Alpha 7 nicotinic acetylcholine receptor and its effects on Alzheimer's disease. Neuropeptides 73, 96-106.

McGough, I. J., and Vecchia, L. (2020). Glypicans shield the Wnt lipid moiety to enable signalling at a distance. Nature 585, 85-90. doi: 10.1038/s41586-0202498-Z

Mii, Y., and Takada, S. (2020). Heparan sulfate proteoglycan clustering in wnt signaling and dispersal. Front. Cell Dev. Biol. 8:631. doi: 10.3389/fcell.2020. 00631

Mohamed, A., and Posse de Chaves, E. (2011). Abeta internalization by neurons and glia. Int. J. Alzheimers Dis. 2011:127984. doi: 10.4061/2011/127984

Munishkina, L. A., Cooper, E. M., Uversky, V. N., and Fink, A. L. (2004). The effect of macromolecular crowding on protein aggregation and amyloid fibril formation. J. Mol. Recognit. 17, 456-464. doi: 10.1002/jmr.699

Oakley, H., Cole, S. L., Logan, S., Maus, E., Shao, P., Craft, J., et al. (2006). Intraneuronal beta-amyloid aggregates, neurodegeneration and neuron loss in transgenic mice with five familial Alzheimer's disease mutations: potential factors in amyloid plaque formation. J. Neurosci. 26, 10129-10140. doi: 10.1523/JNEUROSCI.1202-06.2006

Rawson, J. M., Dimitroff, B., Johnson, K. G., Rawson, J. M., Ge, X., Van Vactor, D., et al. (2005). The heparan sulfate proteoglycans dally-like and syndecan have distinct functions in axon guidance and visual-system assembly in Drosophila. Curr. Biol. 15, 833-838. doi: 10.1016/j.cub.2005.03.039

Rushworth, G. F., and Megson, I. L. (2014). Existing and potential therapeutic uses for $\mathrm{N}$-acetylcysteine: the need for conversion to intracellular glutathione for antioxidant benefits. Pharmacol. Ther. 141, 150-159. doi: 10.1016/j. pharmthera.2013.09.006

Shi, Z. D., Wang, H., and Tarbell, J. M. (2011). Heparan sulfate proteoglycans mediate interstitial flow mechanotransduction regulating MMP-13 expression and cell motility via FAK-ERK in 3D collagen. PLoS One 6:e15956. doi: 10.1371/journal.pone.0015956

Stewart, M. D., and Sanderson, R. D. (2014). Heparan sulfate in the nucleus and its control of cellular functions. Matrix Biol. 35, 56-59. doi: 10.1016/j.matbio. 2013.10.009

Taylor, D. R., Whitehouse, I. J., and Hooper, N. M. (2009). Glypican-1 mediates both prion protein lipid raft association and disease isoform formation. PLoS Pathog. 5:e1000666. doi: 10.1371/journal.ppat.1000666

Timmer, N. M., Herbert, M. K., Kleinovink, J. W., Kiliaan, A. J., De Waal, R. M., and Verbeek, M. M. (2010). Limited expression of heparan sulphate proteoglycans associated with $\mathrm{A} \beta$ deposits in the APPswe/PS1dE9 mouse model for Alzheimer's disease. Neuropathol. Appl. Neurobiol. 36, 478-486. doi: 10.1111/j.1365-2990.2010.01091.x

Tiwari, S., Atluri, V., Kaushik, A., Yndart, A., and Nair, M. (2019). Alzheimer's disease: pathogenesis, diagnostics and therapeutics. Int. J. Nanomed. 14, 5541-5554. doi: 10.2147/IJN.S200490

Van Gool, B., Storck, S. E., Reekmans, S. M., Lechat, B., Gordts, P., Pradier, L., et al. (2019). LRP1 has a predominant role in production over clearance of $\mathrm{A} \beta$ in a mouse model of Alzheimer's disease. Mol. Neurobiol. 56, 7234-7245. doi: 10.1007/s12035-019-1594-2

Wang, C. Y., Cai, X. Y., Wang, R. C., Zhai, S. Y., Zhang, Y. F., Hu, W. J., et al. (2020). Neuroprotective effects of verbascoside against Alzheimer's disease via the relief of endoplasmic reticulum stress in A beta-exposed U251 cells and APP/PS1 mice. J. Neuroinflammation 17:309. doi: 10.1186/s12974-020 $-01976-1$

Wang, Y., Zhang, R., and Huang, Y. L. (2016). Propofol ameliorates ischemia/reperfusion induced cerebral injury by upregulation of microRNA-206 expression. Int. J. Clinn. Exp. Med. 9, 10256-10264. Available online at: https://www.webofscience.com/wos/alldb/fullrecord/WOS:000379156000161.

Wu, Q., Li, Q. F., Zhang, X., Ntim, M., Wu, X. F., Li, M., et al. (2020). Treatment with bifidobacteria can suppress A beta accumulation and neuroinflammation in APP/PS1 mice. PeerJ. 8:e10262. doi: 10.7717/peerj.10262

Yamada, M., and Hamaguchi, T. (2018). The sulfation code for propagation of neurodegeneration. J. Biol. Chem. 293, 10841-10842. doi: 10.1074/jbc.H118. 003970

Yang, W. N., Ma, K. G., Qian, Y. H., Zhang, J. S., Feng, G. F., Shi, L. L., et al. (2015). Mitogen-activated protein kinase signaling pathways promote low-density lipoprotein receptor-related protein 1-mediated internalization of beta-amyloid protein in primary cortical neurons. Int. J. Biochem. Cell Biol. 64, 252-264. doi: 10.1016/j.biocel.2015.04.013

Yu, C., Griffiths, L. R., and Haupt, L. M. (2017). Exploiting heparan sulfate proteoglycans in human neurogenesis-controlling lineage specification and fate. Front. Integr. Neurosci. 11:28.doi: 10.3389/fnint.2017.00028

Zhang, Z. C., Ma, W., Wang, L., Gong, H. S., Tian, Y. M., Zhang, J. S., et al. (2015). Activation of type 4 metabotropic glutamate receptor attenuates oxidative stress-induced death of neural stem cells with inhibition of JNK and p38 MAPK signaling. Stem Cells Dev. 24, 2709-2722. doi: 10.1089/scd.2015.0067

Conflict of Interest: The authors declare that the research was conducted in the absence of any commercial or financial relationships that could be construed as a potential conflict of interest.

Publisher's Note: All claims expressed in this article are solely those of the authors and do not necessarily represent those of their affiliated organizations, or those of the publisher, the editors and the reviewers. Any product that may be evaluated in this article, or claim that may be made by its manufacturer, is not guaranteed or endorsed by the publisher.

Copyright (C) 2021 Ma, Xing, Luan, Zhang, Liu, Fei, Zhang, Liu and Chen. This is an open-access article distributed under the terms of the Creative Commons Attribution License (CC BY). The use, distribution or reproduction in other forums is permitted, provided the original author(s) and the copyright owner(s) are credited and that the original publication in this journal is cited, in accordance with accepted academic practice. No use, distribution or reproduction is permitted which does not comply with these terms. 